Illinois State University

ISU ReD: Research and eData

Theses and Dissertations

4-30-2017

\title{
The digital surgeon's warning: Do disclaimers have a place in beauty and fashion advertising?
}

Jess Gabl

Illinois State University, jess.gabl@outlook.com

Follow this and additional works at: https://ir.library.illinoisstate.edu/etd

Part of the Mass Communication Commons

\section{Recommended Citation}

Gabl, Jess, "The digital surgeon's warning: Do disclaimers have a place in beauty and fashion advertising?" (2017). Theses and Dissertations. 754.

https://ir.library.illinoisstate.edu/etd/754

This Thesis is brought to you for free and open access by ISU ReD: Research and eData. It has been accepted for inclusion in Theses and Dissertations by an authorized administrator of ISU ReD: Research and eData. For more information, please contact ISUReD@ilstu.edu. 
THE DIGITAL SURGEON'S WARNING: DO DISCLAIMERS HAVE A PLACE IN BEAUTY AND FASHION ADVERTISING?

\author{
Jess Gabl
}

86 Pages

The purpose of this study is to investigate the effects of disclaimers of photogenic manipulation, models' body types, and the interaction between the two through the theoretical lenses of social comparison theory and priming effects. In an online experiment, this study employs a 3 (no disclaimer, presence of digital enhancement disclaimer, absence of digital enhancement disclaimer) by 2 (thin model body type and average model body type) factorial analysis to tease apart the effects of disclaimers on consumers (social comparison, self-esteem, and wishful identification) and the organizations that are compelled or choose to employ them (brand attitudes and perceptions of credibility, perceived organizational morality, purchasing intention, and loyalty). The results of this study highlight the implications and considerations for advertisements in the beauty and fashion industries as well as any company that uses digital manipulation on physically attractive models in their advertisements.

KEYWORDS: disclaimers, self-esteem, advertising, brand attitudes, morality, model body types 
THE DIGITAL SURGEON'S WARNING: DO DISCLAIMERS HAVE A PLACE IN BEAUTY AND FASHION ADVERTISING?

JESS GABL

A Thesis Submitted in Partial Fulfillment of the Requirements for the Degree of

MASTER OF SCIENCE

School of Communication

ILLINOIS STATE UNIVERSITY

2017 
Copyright 2017 Jess Gabl 
THE DIGITAL SURGEON'S WARNING: DO DISCLAIMERS HAVE A PLACE IN BEAUTY AND FASHION ADVERTISING?

JESS GABL

COMMITTEE MEMBERS:

Rebecca Hayes, Co-Chair

Megan Hopper, Co-Chair

Caleb Carr 


\section{ACKNOWLEDGMENTS}

The thesis-writing process, and grad school more generally, would not have been possible, and certainly not enjoyable, without the contribution of many people that I am lucky to have in my life. I would first like to acknowledge my mom and dad for encouraging me from a very young age to embrace my intelligence and always thrive to learn and improve. It was their endless pride that motivated me to take school seriously; it was their endless encouragement that helped me through times that I did not feel I performed my best. They blessed me with the opportunity to be the first member of my immediate family to go to a four-year university, and later grad school. I would also like to acknowledge my brother, Danny, for always being someone I have looked up to and ultimately inspiring me to be someone he could look up to as well. I also admire my cousins, Re and Ally, for paving the way for some smart gals in our family. Finally, I felt my grandma's presence guiding me through the final months before graduation and I am grateful for the peace of mind she has always modeled and provided for me.

I was also very lucky that I was able to develop relationships with many professors in the department throughout undergrad and grad school, but the individuals that ended up on my thesis committee were exceptional. Dr. Megan Hopper was the reason I first became interested in studying mass media and was also one of the first professors to suggest that I consider grad school (thank you Dr. Cochece Davis and Dr. Phil Chidester for that suggestion, as well). She expanded my areas of interest and really provided some expertise for the self-esteem component of this study. I would like to thank Dr. Caleb Carr for the rudest awakening ever into the rigor and thoughtfulness that grad-level writing would entail! He challenged me academically for one of the first times in my life and I have endless appreciation for the time and passion he puts into developing his students. Finally, my gratitude also goes to Dr. Rebecca Hayes for really 
providing some baby steps for me throughout this process, remaining patient throughout our endless conversations about this study, and ultimately inspiring an alarming amount of my professional wardrobe.

Beyond the professors that I worked with, though, I was also surrounded by incredible individuals to experience grad school alongside. Thank you, Ryan (Ranger) Cashman, for being the ultimate stress-relief as we (us, our) navigated through, well, the days of our lives. Thank you, (Practical) Adam Mason, for being the most complimentary, to say the least, office mate I could ask for and swinging along on the pendulum with me. Thank you, Jillian (Ray of Sunshine) Joyce, for, well, being a rain of sunshine and letting me always know someone was there if I needed them (often very literally by physically holding my arm). Thank you, Chelsey Eimer, for allowing me to live vicariously through your healthy lifestyle when I ran out of time to take part in one myself. All in all, we all found each other, and we did it right! Finally, thank you, George Bryant, for not leaving any topic of discussion off limits, being a great friend, and truly expanding my thought processes on an endless spectrum of subjects.

Lastly, I would like to thank Anya, Cam, Jordan, Ellen, and Katelyn for providing me sanity outside of the grad school program and reminding me that we are never too old to meet amazing people or to start great friendships.

From the bottom of my heart, thank you, all of you, for filling my life with love, acceptance, and intellectual satisfaction!

J. G. 


\section{CONTENTS}

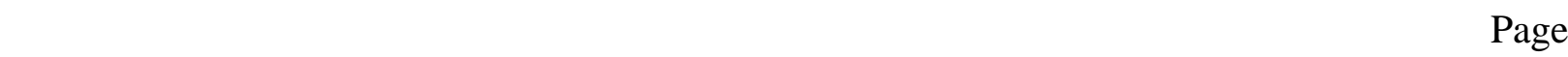

ACKNOWLEDGMENTS

CONTENTS

TABLES Di

FIGURES

CHAPTER I: INTRODUCTION 1

CHAPTER II: LITERATURE REVIEW

$\begin{array}{ll}\text { Defining Self-Esteem } & 4\end{array}$

$\begin{array}{ll}\text { The Current Advertising Environment } & 7\end{array}$

$\begin{array}{ll}\text { Theoretical Framework } & 9\end{array}$

Social Comparison Theory $\quad 9$

$\begin{array}{ll}\text { Wishful Identification } & 14\end{array}$

$\begin{array}{ll}\text { Priming Effects } & 15\end{array}$

$\begin{array}{ll}\text { Disclaimers } & 21\end{array}$

Disclaimers in Beauty and Fashion Advertising 21

Organizational Motivation to Get Involved 23

$\begin{array}{ll}\text { Perceived Organizational Morality } & 23\end{array}$

$\begin{array}{ll}\text { Brand Attitudes } & 26\end{array}$

$\begin{array}{ll}\text { Credibility. } & 26\end{array}$

$\begin{array}{lr}\text { Purchasing intentions. } & 29\end{array}$

$\begin{array}{ll}\text { Loyalty. } & 29\end{array}$ 
Participants

Procedure

Variables and Measurement

Images and Disclaimers

Self-esteem Measures

POM Measure

Advertisement and Brand Credibility Measure

Purchasing Intention Measure

Loyalty Attitude Measures

Demographics

CHAPTER IV: RESULTS

Self-Esteem

Perceived Organizational Morality.

Credibility

$\begin{array}{ll}\text { Purchasing Intentions } & 44\end{array}$

Loyalty

Post-hoc Analysis

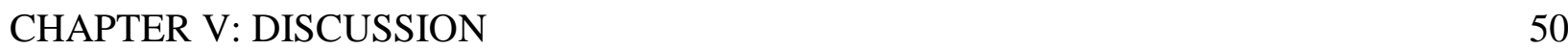

Implications for Social Comparison Theory and Priming Effects $\quad 50$

Photo Disclaimers May Just Be Useless in the World of Advertising 53

The Continuous Importance of Visual Literacy $\quad 54$

Model Body Types are a Strategic Organizational Tool 56 
POM as a New, Important Brand Consideration

$\begin{array}{ll}\text { Limitations and Future Research } & 61\end{array}$

$\begin{array}{ll}\text { Conclusion } & 63\end{array}$

$\begin{array}{lc}\text { REFERENCES } & 64\end{array}$

$\begin{array}{ll}\text { APPENDIX A: ADVERTISEMENT CONDITIONS } & 77\end{array}$

APPENDIX B: STATE APPEARANCE COMPARISON SCALE 79

APPENDIX C: PHYSICAL APPEARANCE STATE ANXIETY SCALE 80

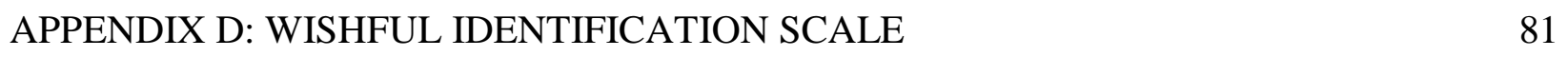

APPENDIX E: PERCEIVED ORGANIZATIONAL MORALITY 82

APPENDIX F: CREDIBILITY 83

$\begin{array}{ll}\text { APPENDIX G: PURCHASING INTENTION } & 84\end{array}$

APPENDIX H: LOYALTY 85

$\begin{array}{ll}\text { APPENDIX I: DEMOGRAPHICS } & 86\end{array}$ 


\section{TABLES}

Table Page

$\begin{array}{ll}\text { 1. Descriptive statistics } & 48\end{array}$

2. Correlation matrix 49 


\section{FIGURES}

Figure $\quad$ Page

1. Proposed hypothesis model 


\section{CHAPTER I: INTRODUCTION}

In today's society it is common place to use physically attractive people as the face for companies and products to promote an ideal lifestyle that may be obtained by becoming a customer. From pin up girls in the 40's to modern day fragrance commercials, 'sex sells' is a strategy that has been proven to be successful (Blair, Stephenson, Hill, \& Green, 2006). However, along with the continued controversy surrounding the ethical decisions behind using oversexualized portrayals of models in advertising, model size and the visual realness of advertisements have landed in the forefront of ethical debates. While society seems to be aware that models are digitally enhanced before the release of advertisements (Bissel \& Rask, 2010; Harrison \& Hefner, 2014), this practice is still frequently blamed for lower physical self-esteem and the physical and mental disorders that are linked to this decreased self-esteem (Shaw \& Waller, 1995; Stice, Schupak-Neuberg, Shaw, \& Stein 1994).

While there are many studies in the fields of psychology, sociology, communication, and business focusing on the excessive sexualization and thinness of female models in advertisements, research addressing how digital enhancement of models might contribute to selfesteem concerns is a relatively new focus and is still developing. There are still mixed interpretations of the organizational ethical dilemmas behind digital enhancements and whether or not consumers are visually literate enough, as has been assumed, to recognize these enhancements (Harrison \& Hefner, 2014). Conflicting opinions also exist over whether there should be legally mandated rules imposed by the government for organizations' advertisements (O’Neil, 2014), or if improving visual literacy could serve a purpose to create distance between consumers and unrealistic image standards (Harrison \& Hefner, 2014; Veldhuis, Konijn, \& 
Seidell, 2014). Disclaimers are in the crossroads of these arguments concerning legal mandates or visual literacy improvement.

Disclaimers and warning labels have been developed for thousands of foods and products. While the functions of warning labels vary, they generally serve an informative function by bringing consumers' attention to potential hazards that could result from consuming or using a product (Stewart \& Martin, 1994). For example, a warning label may bring attention to the dangerous consequences of using a cleaning product in an unintended way or may reiterate the sharpness of the components in a power tool. Disclaimers are different in that they are meant to inform consumers of the limitations of a product to avoid deception or misinterpretations (Green \& Armstrong, 2012). They are usually phrased as, "product-X is [not] Y" (Green \& Armstrong, 2012, p. 1). An example of a disclaimer is when a new pill that regulates a woman's period is not a birth control pill, or when a political comic skit is disclaimed upfront as being fictitious and for entertainment purposes only. For fashion and beauty industries, disclaimers typically include information about the model's health or the image's digital enhancement (O'Neil, 2014); these disclaimers serve to counteract overly-idealized appearance-related messages that consumers are exposed to on a daily basis.

While they have not been mandated in the United States, there are many advertising regulations that include the implementation of disclaimers in other countries. France, for example, has introduced legislation that requires labels on advertisements containing digitally altered or retouched images and the United Kingdom, Brazil, Australia, and Israel are among the countries that are also beginning to propose similar legislature (O'Neil, 2014). The motivation in these countries for requiring disclaimers is to encourage organizations to be more cognizant of the consequences of their advertisements, but the United States is unlikely to get involved in this 
trend since disclaimers infringe on advertisers' First Amendment rights. While there are regulations on advertising and marketing regarding deceit, appeals to children, endorsements, the environment, health claims, 'made in the USA' disclosures, online advertising, and telemarketing (Federal Trade Commission), the United States is comparatively lax on limiting advertisers' free speech. In addition to this First Amendment infringement, there has also been doubt and skepticism surrounding the effectiveness of disclaimers to serve their purpose of shielding consumers from negative physical self-esteem effects (Bissell, 2006; Green \& Armstrong, 2012; Harrison \& Hefner, 2014; Paraskeva, Lewis-Smith, \& Diedrichs, 2015).

This study, grounded in social comparison theory and priming effects, investigates the effects of (a) disclaimers of digital manipulation, (b) models' body types, and (c) the interaction between the two on temporary, appearance-based self-esteem, anxiety, and physical comparisons as well as on brand attitudes and perceptions. This study serves two purposes: first to investigate whether disclaimers on advertisements serve a protective function to alleviate negative influences on an individual's self-esteem, and second to investigate disclaimers from an organizational perspective on disclaimers' impacts on advertising outcomes. 


\section{CHAPTER II: LITERATURE REVIEW}

After specifying the type of self-esteem that is being addressed by this study, the beauty and fashion advertising environment relevant to potential negative influence on this self-esteem will be identified. Then, a theoretical framework will elaborate on how this negative influence takes place and why disclaimers may help prevent decreased self-esteem from advertisement exposure. Next, an overview of the available literature concerning disclaimers in the fashion and beauty fields will be provided. Finally, the potential of disclaimers will be reviewed in the context of how they may influence various brand attitudes (perceived credibility of the advertisement, perceived organizational morality, intent to purchase the product, and an attitude of loyalty toward the brand) held by a consumer.

\section{Defining Self-Esteem}

'Self-esteem' is a term that seems to be mentioned casually throughout tens of thousands of journal articles without a consistent definition being decided upon (Rosenberg, Schooler, Schoenbach, \& Rosenberg, 1995). That said, a variety of self-esteem categories have been identified (personal vs. social, global vs. specific, and state vs. trait) that will allow this study to specify and define the particular type of self-esteem that is relevant.

Breckler and Greenwald (1986) addressed self-esteem as a component of egoinvolvement: the engagement in self-evaluation on the performance of a socially valued skill with consideration of the attitudes and comparisons of other individuals. Their study used egotask analysis, which analyzes how situational and personality factors determine how individuals accomplish a task goal, to identify how self-esteem can be categorized into private (or personal), public (or social), or collective self-esteem. Personal self-esteem refers to the feelings toward oneself as an individual (e.g., I feel I have a number of good qualities; I am a good basketball 
player) and social self-esteem includes the feelings one has about their social presence (e.g., I don't find it hard to talk to strangers). Social self-esteem also includes the "esteem in which he or she holds the shared self-image that constitutes her or his social psychological in-group" (e.g., I am a part of a good basketball team) (Rubin \& Hewstone, 1998, p. 42). Collective self-esteem, while not as commonly discussed as the other two categories, is the idea that individuals usually have some feeling about their individual success in achieving their social group goals (Beckler \& Greenwald, 1986). While social self-esteem could be relevant for this study in terms of relating to the models in an advertisement as being a part of a social group (e.g., gender, race, socioeconomic class), this study is concerned with the personal value judgements one makes about oneself when exposed to advertisements.

Self-esteem can also be described as an attitude. Individuals hold attitudes toward concepts/objects as a whole as well as toward specific parts of those concepts/objects (Rosenberg et al., 1995). Attitudes are created in reference to specific things (objects, people, ideas), have either a positive or negative orientation toward those things, and vary in magnitude (Rosenberg et al., 1995). Based on this attitudinal perspective, self-esteem can be defined as individuals' positive and negative views of themselves. Further, self-esteem can also address oneself as a whole (global self-esteem) or address specific parts of oneself (specific self-esteem), and the intensity of these judgements can vary. With global self-esteem being a broader, overarching opinion of oneself, it has been found to be associated with overall psychological wellbeing (Rosenberg et al., 1995). Specific self-esteem (e.g., academic self-esteem, physical fitness selfesteem) requires more judgement and evaluation and was suggested to be more associated with behavioral outcomes (Rosenberg et al., 1995). This study is concerned with individuals' appearance self-esteem, so a personal, specific self-esteem will be its focus. 
Finally, a third classification of self-esteem is state vs. trait self-esteem. Leary (1999) defines self-esteem as more of an inherently human wanting to feel good about oneself. Two components of this 'feel-good' perspective are state self-esteem ("momentary fluctuations in a person's feelings about her- or himself") and trait self-esteem ("general appraisal of her or his value;" Leary, 1999, p. 33). There may be a reciprocal relationship between state and trait selfesteem in that reoccurring state self-esteem influences may ultimately affect one's opinion of herself or himself, but the 'default' trait self-esteem likely lays a foundation for the effectiveness of stimuli on state self-esteem. Since this study is only looking at how a single advertisement temporarily effects self-esteem, it is addressing state self-esteem.

A concept that is closely related to self-esteem is body image. Similar to self-esteem, 'body image' is another concept that is difficult to choose a single definition of, but there is agreement in the literature that it is a complex interaction between internal biological and psychological elements and external social elements (Usmiani \& Danilu,, 1997). Body image is also considered an ongoing compilation of one's perceived physical self-worth, relating it especially closely to global, appearance-specific self-esteem (Lowery, Kurpius, Befort, Blanks, Sollenberger, Bicpon, \& Huser, 2005). While self-esteem and body image are frequently covered together in research (Clay, Vignoles, \& Dittmar, 2005), the direction of influence between the two concepts is unclear (Usmiani \& Daniluk, 1997). With the current study using a singleexposure stimulus and focusing on temporary, state effects, it is appropriate to focus on a very particular component of self-esteem, rather than the more global internalization of body image. This study is not suggesting, however, that the phenomena discussed are exclusive to selfesteem, since self-esteem and body image are often observed as being closely intertwined and 
influenced together (Clay, Vignoles, \& Dittmar, 2005; Lowery et al., 2005; Usmiani \& Daniluk, 1997).

Rubin and Hewstone (1998) argue that only addressing one categorical component of self-esteem at a time is a serious limitation of early research on self-esteem since these elements occur simultaneously. With that in mind, when 'self-esteem' is mentioned henceforth, unless stated otherwise, it is referring to a personal, appearance-specific, state self-esteem.

\section{The Current Advertising Environment}

Recalling earlier findings about photo manipulation (Shaw \& Waller, 1995; Stice et al., 1994), advertising is frequently blamed for negative impacts on self-esteem and for the mental and physical disorders linked to those negative feelings. It has been a well-known strategy in advertising and marketing to portray an ideal lifestyle of those who are supposedly using a company's product to insinuate a message that if the consumer also uses this product, their life will improve and more closely mirror that of the advertisement (Richins, 1991). In addition to portraying ideal lifestyles, the characters in advertisements, if not physically attractive celebrities, are often physically attractive models that further communicate this idea that a consumer needs the company's product to achieve a desired social status (Bower, 2001). In addition to an idealized life picture and atypically physically attractive models, advertisers have been using hair, makeup, and lighting techniques to further enhance the attractiveness of the overall advertisement message for decades (Slater, Tiggemann, Firth, \& Hawkins, 2012).

Even with these more traditional practices still being utilized, the continuous development and increased availability of new technology has trumped the effectiveness of these practices, rendering them insufficient for portraying a professional, legitimate image in commercialization (Harrison \& Hefner, 2014). These technologies have simply made it near 
impossible to achieve beauty standards or commercialized expectations without their use. While computer effects (also referred to as "airbrushing, Photoshopping, retouching, photo manipulation, photo tampering, digital forgery, and image editing;" Harrison \& Hefner, 2014, p. 134) may be deceptive in food, home living, and other industries, using these effects on models' appearances raise unique ethical concerns in the beauty, fashion, health, and entertainment industries. With knowledge of the tools and strategies available to advertisers, it is reasonable to assume advertising is not often perceived as completely honest or realistic. However, studies addressing what this perception may mean for consumers and companies yield inconsistent findings on self-esteem and brand attitudes, which will be explored further later in this study.

Even though consumers often acknowledge the models in advertisements are underweight and undergo hours of makeup, hair, and digital perfecting, the models in these advertisements are still perceived as real and representative of beauty standards (Arroyo, Segrin, \& Harwood, 2014; Bissell \& Rask, 2010; Slater et al., 2012; Sohn, 2009). It is then extremely unlikely, if not impossible, that consumers are actually able to match this level of perfection (Richins, 1991; Slater et al., 2012), causing an increase in the distance between one's ideal self (the attributes that are perceived by yourself or others as ideal to possess) (Higgins, 1987) and actual self (the attributes that yourself or others believe you actually possess; Higgins, 1987) (Richins, 1991; Sohn, 2009). The further one feels her or his appearance is from the ideal body standard, the more likely health, well-being, social, and judgmental outcomes are to be negative (Arroyo et al., 2014, Aubrey, 2006; Aubrey, 2007). The support of these negative outcomes provides an explanatory link between advertisements and lowered self-esteem by identifying the likely distance a consumer perceives between her or his actual self and ideal self, a thought process that will be developed further in a later discussion framed by social comparison theory. 


\section{Theoretical Framework}

It is important to better understand the cognitive processes that take place when a consumer interprets media messages. While there are many theories and effects that have been studied in psychology, sociology, communication, business, and other disciplines that suggest how interpretations and perceptions are formed, two that are especially appropriate for this study are social comparison theory and priming effects (Meyer \& Schvaneveldt, 1971. Social comparison theory (Festinger, 1954) elaborates on why and how consumers are influenced by celebrities, models, or other actors in advertisements, while priming effects offers explanation of how different thoughts and feelings are activated through sequences of exposure, which leads to the potential consequences of disclaimers.

\section{Social Comparison Theory}

Social comparison theory (Festinger, 1954) has a number of assumptions based on the innate, human drive to have our opinions (cognitive thoughts and beliefs) and abilities (what we are capable of doing) evaluated. Research by Hakmiller in the 60s provided findings that suggested the motive to enhance or protect self-esteem through comparison (Suls \& Wheeler, 2012). Although self-esteem was not an original element of social comparison theory, this research was the beginning of it later becoming a central component. According to social comparison theory, opinions are not the same as evaluations since they do not provide any "clear ordering of criterion" (p. 118). The example Festinger (1954) uses is if someone evaluates heror himself as being good at writing poetry, the evaluation would depend largely on others' opinions of her or his poetry abilities. However, an evaluation of running abilities can be evaluated much more clearly based on time or distance. That said, evaluation would also likely require times and distance of others to compare one's own running abilities to. So, when there 
are no means available to evaluate opinions and abilities objectively and non-socially, "people evaluate their opinions and abilities by comparison respectively with the opinions and abilities of others" (p. 118). However, social comparison theory can be observed in evaluating more than just specific abilities or cognition; it is relevant to much broader characteristics that are present with even casual exposure to other people (Morse \& Gergen, 1970).

Social comparison theory (Festinger 1954) goes on to suggest that individuals have a tendency not to compare themselves with others who are perceived as too divergent, in either direction, from their own abilities. This restraint is not as apparent with divergent opinions, however, since they are more easily changed. For example, if someone is only average at running, they are unlikely to compare their running abilities with an Olympic runner, since changing her or his abilities that drastically is incredibly difficult. However, opinions can be changed relatively easily since they are completely cognitive and do not rely on abilities or other restraints, but that still does not mean opposing opinions are easy to accept (Festinger, 1954). Therefore, people have a tendency to be attracted to groups that are similar to them with respect to opinions and abilities. Further, Schachter (1959) suggested that being in similar circumstances or experiencing similar emotions also leads to affiliation with others.

When differences within a group arise, there is a pressure toward uniformity (Festinger, 1954). This pressure is usually in an upward direction since competitive human nature causes individuals to want to be at a point on the 'ability continuum' slightly better than those they are comparing themselves to. Again, this upward pressure is not as prominent when considering one's opinions, since they are easier to change than one's performance (Festinginer, 1954). This 'upward comparison' caused by one's desired location on an ability continuum of a group does seem to plateau eventually, though, when an individual evaluates another's ability as being 
considerably higher than her or his own. According to Festinger (1954), evaluation and comparison stops in instances like this without any hostility and with acknowledgement of the other's superiority. When one does compare her- or himself upwardly as a means for evaluation, it can result in negative feelings, such as lowered self-esteem (Martin \& Gentry, 1997; Richins, 1991).

While Festinger (1954) thoroughly explained this self-evaluation concept as a motive for social comparison, researchers since have added two additional motives. Self-improvement can occur when an individual is inspired to improve a particular attribute after an exposure that results in an upward-comparison (Martin \& Gentry, 1997). Usually this inspiration comes from comparison with others who are perceived as a non-competitor, whereas a target that is perceived as threatening is usually avoided. For example, Lockwood and Kunda (1997) found that firstyear college students felt inspired and motivated to succeed after reading about an exceptional fourth-year 'superstar' student's success that they compared upwardly to, largely because improvement was still attainable or the experience gap lessened the threat of the fourth-year student. Similarly, "an advertisement model is most likely to be perceived as a non-competitor" (Martin \& Gentry, 1997, p. 22), since the model is not a part of a consumer's social group. Selfesteem can actually be enhanced when self-improvement is an individual's motive of comparison due to the inspiration to improve (Martin \& Gentry, 1997). These motives are also reflective of the suggestion that social comparison theory must be studied through the lens of individuals' internal thought processes and unique psychological makeup, rather than just through social influence (Morse \& Gergen, 1970).

Along with self-evaluation and self-improvement, the third motive for comparison is selfenhancement. Martin \& Gentry (1997) define this as "a biased attempt to maintain positive views 
of oneself to protect or enhance self-esteem” (p. 22). While this motive was observed the least, there were instances where an individual would avoid upward comparisons with an advertisement model by recognizing that the 'surrounding dimensions' (e.g., model's age, advertisement's setting) seemed dissimilar or discounting the beauty of the model (e.g., acknowledging the extreme diet the model is likely on or how unrealistic the model's appearance is). Self-enhancement, then, is a deliberate motive that involves recognizing the dissimilarities with a comparison target to ultimately avoid upward comparison and protect self-esteem. The presence of a disclaimer on an advertisement may encourage this type of thought process by bringing attention to digital enhancement of the model(s).

Festinger (1954) also included in social comparison theory that the more important an ability or opinion is to an individual, the more pressure there is to reduce differences surrounding that ability or opinion and the more drive there is to evaluate oneself. The same goes for when an individual finds a group they are in particularly attractive; the group will become more important for comparison and evaluation (Festinger, 1954). With that in mind, it is reasonable to say that physical attractiveness is especially important in American culture, with so many media messages emphasizing appearance and (for women) thin body standards (Greenwood, 2009; Hoffner, 1996; Hoffner \& Buchanan, 2005; Martin \& Gentry, 1997; Richins, 1991; Sohn, 2009). Therefore, consumers have a tendency to compare themselves to physically attractive advertisement models even when they do not find the models to be realistic or similar to them (Richins, 1991; Sohn, 2009). If these advertisements are used for purposes of self-evaluation, the upward-comparison with these highly physically attractive models can result in lowered selfesteem, recalling Martin and Gentry's (1997) suggestion. Richins (1991) posited that marketers may desire these negative feelings from their consumers since they may encourage customers to 
buy their product that is being advertised as a 'cure' to this negative feeling. This relies on a selfimprovement motivation on the consumers' end, but many consumers are not convinced by advertisements that their product will yield the desired benefit (Richins, 1991).

Sohn (2009) observed that mere exposure to upward-comparison targets is not the sole indicator of potential negative influences on self-esteem. Involvement with media messages (the amount of cognitive processing that is required) also influences how the social comparison process affects an individual's self-esteem. Other considerations that social comparison theory does not account for are why individuals have different motivations for comparison or how social comparison habits evolve throughout an individual's life. Limitations aside, social comparison theory has many implications that are appropriate for the current study, especially when considered alongside priming effects. The current study intends to observe the effects of a disclaimer through a lens provided by social comparison theory by asking:

RQ1: How does the presence of a disclaimer influence a consumer's comparisons with advertisement models?

Some early research on social comparison theory eluded to the idea that social comparison can also result in cognitive and behavioral assimilation or contrast with the comparison target, a concept that Collins, (1996), later revisited and found support for. Once assimilation and contrast were again identified as outcomes of social comparison, connections to priming effects were drawn (Suls \& Wheeler, 2012). This was because priming has the ability of adjusting a potential comparison target to being perceived as closer or further away from oneself, thereby affecting later assimilation or contrast. Before further unraveling priming effects, however, it is important to touch on wishful identification, a concept that is closely related to social comparison theory, as it will be a critical component of the methods for this study. 


\section{Wishful Identification}

Wishful identification is "the desire to be like or act like a character" (Hoffner \& Buchanan, 2005, p. 325). It is a concept that has largely been studied through children's and adolescents' exposure to television characters and as the process in which these young media audiences participate vicariously with television programs (Greenwood, 2009; Hoffner, 1996; Hoffner \& Buchanan, 2005). However, there are some implications of wishful identification that can be applied to the current study's observation of a magazine-style advertisement as Greenwood (2009) found that entertainment and fashion magazine models encourage the same type of social comparison processes as wishful identification. Hoffner and Buchanan (2005) found that there is a common desire to be like others who are dissimilar from them in important aspects like success, talent, or appearance. For this desire to take place, though, individuals must perceive some type of initial similarity to the wishful target, even if it is something as simple as being the same gender (Hoffner \& Buchanan, 2005). This finding seems to contradict the social comparison theory assumption that individuals prefer to compare themselves to targets that are perceived as similar, but it echoes the findings regarding individuals' tendency to compare themselves with unrealistic and different advertisement models.

Wishful identification takes social comparison a step further, though, to say that when individuals find a socially attractive target for comparison, they may change their appearance, behavior, or even attitudes to emulate that target. Since magazine advertisements allow less information about attitudes and behavior of the model, it is likely that wishful identification with magazine models takes place primarily with appearance standards. Moreover, Hoffner (1996) found that for females, appearance is often the only factor that leads to wishful identification by other females. Reflective of social comparison theory, increased wishful identification with a 
physically attractive female character leads to negative body self-esteem when the characters are recognized as being dissimilar (Greenwood, 2009). In the same way that disclaimers may encourage a self-improvement, rather than a self-evaluation, motive for comparison with advertisement models, they may also point out dissimilarities prior to the formation of wishful identification, allowing a consumer to avoid negative consequences of this phenomena. Based on this path of reasoning, the current study poses the following question:

RQ2: How does the presence of a disclaimer influence a consumer's wishful identification with advertisement models?

\section{Priming Effects}

The concept of priming was first introduced by Meyer and Schvaneveldt (1971) and initially was researched in the psychology discipline (Higgins, 1987; Higgins, Bargh, \& Lombardi, 1985; Schvaneveldt \& Meyer, 1973). Priming effects have since been described in relation to political communication (Goidel, Shields, \& Peffley, 1997; Iyengar, Peters, \& Kinder, 2006; Scheufele \& Tewksbury, 2007), advertisements (Boush, 1993; Forehand \& Deshpande, 2001; Pechmann \& Knight, 2002; Wang, 2012; Yi, 1990), and other mass media messages. While these studies may have focused on different components and outcomes of a priming effect, they all are based on the premise that a priming effect occurs when an initial stimulus (be it a word, picture, verbal message, etc.) activates semantically related ideas, thoughts, feelings, or related behaviors for a limited, generally short, period of time (Jo \& Berkowitz, 1994).

Participants in an experiment conducted by Meyers and Schvaneveldt (1971) performed reaction-time tasks where they were exposed to two words, one at first and then a second along with it, and had to distinguish if the words were associated or not. Results indicated participants were able to make this distinction more quickly when the words were associated. This finding 
suggests that our memory is organized semantically, where the 'distance' between two related words is shorter than the 'distance' between two unrelated words (Meyer \& Schvaneveldt, 1971). Once the first word is stated, our memory structure allows us to access related words quicker since they are 'closer,' whereas unrelated words are 'farther away.' In other words, an initial word or thought allows for quicker access to similar words or thoughts than for different words or thoughts, and "any retrieval operation that is required sufficiently soon after another operation will generally depend on that first operation" (Meyer \& Schvaneveldt, 1971, p. 232;

Schvaneveldt \& Meyer, 1973). Schvaneveldt \& Meyer (1973) explained this spreadingexcitation model (not yet referred to as 'priming effects') where retrieving information from one area of memory spreads excitation to other 'near' memories, likely of similar meaning, and facilitates retrieval in these newly activated, related areas of memory.

Findings reflective of the spreading-excitation model were found when participants were exposed to an ambiguous stimulus (one that could be interpreted in multiple ways) after being primed by a construct. For example, after being exposed to words like, "bold, courageous, and brave," participants perceived the description of a person that takes a lot of risks as being adventurous, whereas participants originally exposed to words like, "careless, foolhardy, and rash," perceived the same description as being reckless (Higgins, Barge, \& Lombardi, 1985, p. 63). However, the study also found that priming effects dissipate over time and that the rate of this dissipation depends on how frequently or recently the construct has been primed. This study also suggested that there is a "fixed, maximum level of action potential or accessibility that a construct reaches after being primed" (Higgins, Barge, \& Lombardi, 1985, p. 66), and this maximum level of a priming effect depends on the individual (Higgins, 1987). 
Higgins (1987) extended work on priming effects by applying them to self-discrepancy. Self-discrepancy theory posits that there are three domains of the self (actual, ideal, and ought) and two standpoints on the self (one's own opinion and the opinion of others). A 'self-concept' is comprised mostly of the actual/own and actual/other combinations of domains and standpoint, while 'self-guides' are comprised of the ideal/own, ideal/other, ought/own, and ought/other perspectives (Higgins, 1987). "Self-discrepancy theory postulates that we are motivated to reach a condition where our self-concept matches our personally relevant self-guides" (Higgins, 1987, p. 321), so a 'self-discrepancy' is the level of mismatch between a self-concept and self-guide. Relating back to priming effects, a self-discrepancy is a type of construct that can be activated through frequent or recent priming. However, priming these types of constructs typically results in feelings of discomfort, depending on the magnitude of the discrepancy (Higgins, 1987). The potential negative feelings that are activated by priming self-discrepancies may be closely linked to comparison and self-esteem. If consumers are exposed to models in an advertisement that are reflective of their ideal/own self guides and they believe it does not match their self-concepts, this self-discrepancy activated by upward-comparison is likely reflective of, or further impacts, their self-esteem. In this way, Higgins (1987) begins to offer links between priming effects, social comparison, and self-esteem.

Priming effects transitioned from the psychology discipline to communication primarily through political communication and connections to agenda setting theory (Goidel, Shields, \& Peffley, 1997; Iyengar, Peters, \& Kinder, 2006; Scheufele \& Tewksbury, 2007). McCombs and Shaw's (1972) agenda setting theory has often been summarized as telling us what to think about, but not necessarily 'what' to think, but priming effects became an extension of this theory when it was observed that news content may suggest certain "benchmarks for evaluating the 
performance of leaders and governments" (Scheufele \& Tewksbury, 2007, p. 11). In other words, while media agenda setting may make certain issues seem more important to an audience, media priming shapes the considerations and judgements that people find relevant to those issues (Scheufele \& Tewksbury, 2007). This suggests a reciprocal relationship between agenda setting and priming.

However, it also may be that priming mediates agenda setting effects by taking into consideration the individual's opinions and interests on an issue (Goidel, Shields, \& Peffley, 1997; Iyengar, Peters, \& Kinder, 2006). Though Iyengar, Peters, \& Kinder's (2006) study was on a presidential election, their general suggestion that extended media coverage may activate certain concepts and make them automatically more accessible can be transferred to other media messages. Relevant to this study, the extensive and persuasive media and advertising inclusion of thin ideal models may make upward-comparisons and self-discrepancies more available for priming.

While priming effects have been observed in the advertising industry by addressing slogans (Boush, 1993), ethnicity and race (Forehand \& Deshpande, 2001), and controversial products, such as cigarettes (Pechmann \& Knight, 2002), most relevant to this discussion is the literature that has observed how priming can impact self-objectification differently for men and women. Self-objectification occurs when the saturation of sexually objectifying messages teaches women to see themselves as a physical objects to be assessed by others (Fredrickson \& Roberts, 1997). While the current study is not measuring self-objectification, self-objectification is considered a negative consequence of consuming today's media messages (Aubrey, Henson, Hopper, \& Smith, 2009), much like this study speculates that media messages have a negative impact on self-esteem. Aubrey et al. (2009) found that "exposure to objectified images may 
have temporarily primed participants' recognition that women's value is at least partially connected to their bodies" (p. 280), so this may provide support for the idea that attitudes toward oneself, such as discrepancies and self-esteem, may also be influenced when exposed to upwardcomparison priming. This study also found, echoing other research, priming effects are shortterm, but have long-term implications due to the frequency of message exposure in current media diets (Aubrey et al., 2009). Though this study spoke primarily to a college student's media diet, media messages are not solely responsible for college students' self-esteem, as this is an accumulation of a multitude of complex relationships and influences.

Roberts and Gettman (2004) also were interested in the self-objectification consequences of priming effects, but wanted to see how intense the priming effect would have to be and whether priming effects impacted men the same way they did women. Overall, they found that simple words on a page that highlight a body's physical appearance could trigger a state of selfobjectification and that women are usually more susceptible to this effect due to being exposed to self-objectifying priming messages more frequently. This study also focused on the idea that priming is an "incidental activation of knowledge structures" (Roberts \& Gettman, 2004, p. 19), meaning it is not a process that takes place purposely. The discussion goes on to suggest that if women (and men for that matter) could educate themselves to absorb media messages through a more critical, aware lens, they could combat the negative effects of self-objectification. However, consumers are often not completely cognizant of every message they are consuming; casually glancing at a magazine cover in a grocery store or listening to a song on a drive home from work could prime sequential actions (Roberts \& Gettman, 2004).

Priming effects offer an interesting perspective on studying disclaimers. While most research that has been done on the influence of priming has focused on two separate exposures 
quickly following each other, Yi (1990) mentions that advertisements can be evaluated based on the constructs activated prior to, or accompanying the advertisement. Since a disclaimer is printed on an advertisement itself, it is consumed simultaneously with the advertisement, rather than before it, so it is important that priming constructs can accompany the 'latter' message. Research has suggested that being more blatant in labeling disclosures may initiate visual priming that forms better brand attitudes than placing disclosures in inconvenient spaces (Wang, 2012). Recalling the earlier purpose of a disclaimer to inform a consumer about a product or advertisement to avoid deception or misinterpretations, it seems that a disclaimer could certainly be used strategically to prime certain thoughts or acknowledgements. Therefore, although disclaimers of photo manipulations have not yet been studied through a lens of priming effects, this perspective seems merited.

Recalling the tendencies for social comparison to either lead toward assimilation with a comparison target or contrast against a comparison target, priming has the ability to increase the likeliness of assimilation or contrast taking place. Priming has the ability to 'move' the comparison target closer to seem more similar or appropriate for evaluation, thus leading to assimilation (Suls \& Wheeler, 2012), or it could 'displace' the comparison target to be perceived as less similar or inappropriate for evaluation, which would encourage contrast (Lombardi, Higgins, \& Bargh, 1987). Ultimately, disclaimers may allow for priming in relation to social comparison tendencies to either assimilate or contrast, but there is little research yet that suggests what this relationship will look like; the current study aims to further identify this relationship. More specifically, the current study wishes to examine this relationship's outcomes on selfesteem, the foundation for a final research question:

RQ3: How does the presence of a disclaimer influence a consumer's self-esteem? 


\section{Disclaimers}

While research does exist on the application of disclaimers in the beauty and fashion advertising industry, there are often conflicting results or results without much explanation. Despite this, the application of social comparison and priming effects suggests that disclaimers are an important consideration for beauty and fashion advertising and visual literacy.

\section{Disclaimers in Beauty and Fashion Advertising}

Since the United States produces messages and products that are marketed internationally, there is a growing pressure from other countries that have begun implementing advertising regulations (e.g., on model body types, disclaimers, and digital enhancements) to enforce similar regulations (O’Neil, 2014). However, though other countries seem to be acting in goodwill with consideration of advertisements' effects on self-esteem, findings indicate that advertising disclaimers may not accomplish what they set out to (Bissell, 2006; Harrison \& Heffner, 2014). Studies have even found that the presence of a disclaimer can increase upwardcomparisons and negative self-evaluations (Bissell, 2006; Harrison \& Heffner, 2014). A possible explanation of this is that labeling an image as being digitally perfected then primes a viewer into thinking even more highly of that image, whether for visual, professional, or status reasons, and then evaluates her- or himself against an even more dissimilar perception of the model than is portrayed. A second explanation is that cultivation effects simply overpower a disclaimer's purpose (Bissell, 2006; Paraskeva, Lewis-Smith, \& Diedrichs, 2015), or that disclaimers go unnoticed in beauty and fashion advertisements (Paraskeva, Lewis-Smith, \& Diedrichs, 2015; Slater, Tiggemann, Firth, \& Hawkins, 2012). When disclaimers are put in place with the intention of decreasing negative self-evaluations through social comparison, but then actually 
increase these evaluations, it is referred to as a 'boomerang effect' (Ata, Thompson, \& Small, 2013).

Along with a potential boomerang effect, another concern for disclaimers' place in beauty and fashion advertising is whether the physical, visual components of the disclaimer could take away from the visuals of the advertisement and negatively impact the brand advertised. However, when warnings were printed in various locations on a fashion magazine advertisement, it had no effect on a viewer's ability to recall the brand or product (Slater et al., 2012). In addition to being discrete enough to not distract from products, disclaimers are an affordable and easy way for companies to attempt to relieve the negative self-esteem consequences from upward comparisons, if the disclaimers are effective (Green \& Armstrong, 2012).

Although some research has observed a boomerang effect of disclaimers (Bissell, 2006; Harrison \& Hefner, 2014), other research has found that disclaimers do successfully decrease the amount of upward-comparison and negative self-evaluation when one is exposed to an advertisement (Paraskeva, Lewis-Smith, \& Diedrichs, 2015). This research has found that the logical purpose of a disclaimer is to label an image as being digitally enhanced, encouraging viewers to accept the image as unrealistic and not appropriate for self-evaluation, or else encouraging more of a self-enhancement motive for comparison. Slater et al. (2012) found consumers viewed images as less realistic and relevant when they had disclaimers that reminded women that the image was not realistic or attainable and that it would be inappropriate to desire the appearance. Veldhuis, Konijn, and Seidell (2014) found similar results, reporting more positive moods and less body dissatisfaction when a label was present. Opposed to a boomerang effect, these findings may be referred to as a 'protective effect,' where disclaimers have the 
ability to bring attention to the dissimilarities of a model and discourage self-evaluation based on upward-comparison. These conflicting effects will be further analyzed here, through RQ1.

\section{Organizational Motivation to Get Involved}

There are two primary reasons organizations would feel motivated to voluntarily include disclaimers, thus improving their means of advertising and persuasion to be more ethical and less physically or emotionally dangerous to their consumers. The first is that companies, especially larger and more successful ones, might feel some pressure to be socially responsible (Gildea, 1995). This includes using their platform and finances to improve the communities that they function within and having an unselfish consideration of the greater good. This ties in closely to the second reason an organization should feel motivated to act in such a way that improves relationships with customers and benefits the company in terms of consumer attitudes and behaviors (Gildea, 1995); these improvements influence a company's profits and success. While organizations may be hesitant to get on board with the implementation of disclaimers, even if they are proven to improve or protect the self-esteem of consumers, benefits for their brand may provide more motivation. This study examines brand attitudes in the context of perceived organizational morality, perceived credibility of the advertisement, intent to purchase the product, and loyalty to the brand.

\section{Perceived Organizational Morality}

While many terms (corporate social responsibility, goodwill, ethics, etc.) have been used to describe various types of perceived duties of corporations who have access to a large amount of resources, the current study focuses on perceived organizational morality. However, it is still important to review similar concepts to clarify how perceived organizational morality is unique. 
Corporate social responsibility (CSR) has evolved from being primarily concerned with economic and legal obligations to also including ethical and philanthropic responsibilities as well (Carroll, 1991); most relevant to perceived organizational morality are the latter two. The ethical component of CSR includes standards, norms, and expectations of all stakeholders of an organization and includes staying current with new values or societal expectations (Carroll, 1991). However, these are separate from standards that are legally required of the organization and are often difficult for organizations to identify and react to appropriately (Carroll, 1991). Philanthropic responsibilities promote goodwill through financial resources and donations of time (Carroll, 1991); more specifically, this 'corporate goodwill' can be defined as "all donations made to charitable organizations and other worthy causes that also enhance the reputation of the corporate donor (Webb \& Farmer, 1996, p. 30).

While community involvement may reflect 'good citizenship' of an organization, it is also becoming a necessary organizational characteristic for competitive advantages (Ellemers, Kingma, Van de Burgt, \& Barreto, 2011). Ellemers et al. (2011) suggests that the perceived morality behind an organization's involvement in CSR-activities may enhance employees' attitudes toward working for the organization and improve organizational performance. The current study extends this reasoning to an organization's consumers and defines perceived organizational morality (POM) as a consumer's belief that an organization's actions are genuinely guided by honesty, sincerity, and trustworthiness. Since POM internal to an organization has the ability to enhance employee attitudes toward her or his place of work, this POM that is external to an organization might have the ability to enhance consumer attitudes toward a brand. 
While POM is a concept that has been studied as a byproduct of CSR (Ellemers et al., 2011), the current study is less concerned with CSR-activities such as financial donations and volunteerism and more concerned with activities that are more appropriately categorized as acting with good corporate moral responsibility (CMR). CMR is closely related to POM in that it is a concept based on a company's employees using an organization's resources intentionally and responsibly to avoid negative outcomes for its employees and consumers (Velasquez, 2003).

CMR includes the internal workings of an organization and their messages (ie. advertisements) in evaluating an organization's morality, whereas CSR limits this mostly to the external donations and events that an organization chooses to involve itself with, so it seems appropriate for the current study to observe POM through a CMR lens that can account for the organization's consideration of its audiences when constructing advertisements for its products. However, POM and CMR are not explicitly linked; it is possible for a company's employees to act with strong CMR intentions and for consumers to not perceive their actions as being honest or sincere, much like it is possible for the opposite scenario to occur. While the current study suggests that CMR should be an internal organizational priority with the consideration of consumers' POM, one is referring to a company's employee's actions and motivations, while the latter is referring to consumers' perceptions and interpretations.

Since it has been suggested that advertising practices (e.g., photo manipulation) frequently do lead to upward-comparisons and impact self-esteem negatively, and that advertisers often are aware of this effect (Richins, 1991), then not acting in accordance with the duties to address and prevent these negative consequences can be identified as acting immorally (Velasquez, 2003). However, if disclaimers are perceived as an organization's attempt at acting morally and priming consumers' perceptions to discourage upward-comparison and protect self- 
esteem (as this is the intended purpose of a disclaimer for the current study), a consumer might have higher perceptions of morality for that organization. Therefore, the following hypothesis is posed to further investigate this:

H1: Individuals will perceive a company with a disclaimer on its advertisement as having more POM than a company without a disclaimer on its advertisement.

\section{Brand Attitudes}

One of the most foundational goals of advertising is to persuade. Companies want to persuade consumers to buy a product, subscribe to a service upgrade to newer innovations, and so on. When physically attractive, thin models are used in advertisements, they can actually be detrimental to persuasive effects (Bower, 2001; Dickinson-Delaporte, Ford, \& Gill, 2014). Obermiller, Spangenberg, and McLachlan (2005) found when researching the negative attitude effects and skepticism of advertisements that many consumers have a difficult time finding advertisements to be truthful, which made them "like it less, believe it less, and believe it is less influential" (p. 15). Through assumptions of social responsibility theory and priming effects, disclaimers may be able to counteract some of the skepticism that surrounds advertisements to improve their effectiveness in terms of perceived credibility of the advertisement and brand, purchasing intentions of the product or service being advertised, and loyalty to the brand. Credibility, purchase intent, and loyalty also are likely to interrelate and may interact with selfesteem and POM.

Credibility. Advertising credibility can be broken into brand credibility and advertisement credibility. Brand credibility is described as "the extent to which the consumer perceives claims made about the brand in the ad to be truthful and believable" (MacKenzie \& Lutz, 1989, p. 51); the 'truthful' component of this definition may rely more on the honesty of 
the brand, while the 'believable' component of this definition is more likely dependent on the effectiveness of the advertisements that the brand produces. The current study refers to brand credibility in the same respect that Flanagin and Metzger (2007) differentiate 'sponsor credibility:' a consumer's evaluation relies on the brand's reputation and her or his own experiences with the brand.

Advertisement credibility refers to a consumer's favorable or unfavorable reaction to an individual advertisement itself (Lutz, 1985). For the purpose of the current study, advertisement credibility is parallel to 'message credibility,' which rely on on "aspects of the message itself, for example, information quality, accuracy, currency, and language intensity" to develop "perceptions of the competence and/or trustworthiness of messages" (Flanagin \& Metzger, 2007, p. 322). An advertisement would count as the 'message' in this explanation.

A duel mediation hypothesis (see MacKenzie, Lutz, \& Belch, 1986) exists that describes the relationship between advertisement influences/attitudes and brand influences/attitudes. Important to the current study, attitudes toward an advertisement had a strong mediating relationship with attitudes toward a brand (Brown \& Stayman, 1992; MacKenzie, Lutz, \& Belch, 1986). Since the current study is focused on a consumer's perception of an advertisement's and brand's credibility, perceived credibility can be described as a parallel concept to advertisement and brand attitudes described by MacKenzie, Lutz, and Belch (1986). Therefore, in accordance with the duel mediation hypothesis, while advertisement credibility and brand credibility are separate components of credibility, they likely are both influenced by an advertisement's physical components and preexisting brand attitudes. Further, the perception of advertisement credibility may influence the perception of brand credibility. Inspired by components of the duel mediation hypothesis, the following hypothesis is proposed: 
H2a: An advertisement's credibility will be positively correlated with the advertised brand's credibility.

When thin, digitally-enhanced models are the target of upward-comparison selfevaluation, consumers view the model and the advertisement both as being less credible and less persuasive (Bower, 2001; Lin \& Tsai, 2006). This may also then lead to a perception of the brand being less credible and less persuasive. If a disclaimer alleviates this upward-comparison, it may improve the advertisement's credibility. Further, while a disclaimer does not make an image look any more realistic, the acknowledgement of unrealistic aspects of an advertisement may increase the perception of honesty or truthfulness of the brand, which are key components of credibility, therefore:

H2b: An advertisement will be perceived as more credible when a disclaimer is present. H2c: A brand will be perceived as more credible when a disclaimer is present on its advertisement.

There also may be a relationship between POM and credibility. Recalling that CMR includes intentional avoidance of any negative consequences for consumers (Velasquez, 2003), consumers evaluate advertisement credibility based partially on perceptions of the advertiser's motivations and intentions (Cotte, Coulter, \& Moore, 2003), which might also influence their perceived organizational morality. This means that if organizational members act with high regard of CMR and this is accurately perceived by consumers, the consumers will view more positively perceive the morality of the organization, thereby increasing the perceived credibility of that organization. That said, "if consumers perceive an ad as credible, they are more likely to hold a positive attitude toward the advertisement and sponsor" (Cotte, Coulter, \& Moore, 2003, p. 366). Therefore, it makes sense that there may be reciprocal relationship where perceived 
credibility of a brand or advertisement leads a consumer to also perceive the morality of an organization more. Thus, the following is predicted:

H3: An advertisement's credibility will be positively correlated with the advertisement's brand's POM.

H4: A brand's POM will be positively correlated with the brand's credibility.

Purchasing intentions. Especially noticeable in the beauty industry, the perceived realism of an advertisement is very influential on a consumer's purchasing intentions (Richins, 1991; Sohn \& Youn, 2013). When, for example, an individual is in the makeup aisle of a store and bombarded with dozens of companies' advertisements, it is likely that he or she will choose the product that seems the most credible and likely to yield the results it is promoting. Companies that are already perceived as being more credible (truthful and believable) may have an easier time being perceived as having more realistic advertising. Since realism, and ultimately credibility, is a key determining factor of whether a customer will purchase a product (Richins, 1991; Sohn \& Youn, 2013), credibility should positively influence purchasing intention. As such, the following is proposed:

H5: Consumers will be more likely to report an intent to purchase a brand's product the more they perceive the brand as being credible.

Loyalty. Loyalty has been defined in two primary ways: the stochastic approach (where loyalty is a behavior characterized by repeat purchases from the same brand) and the determinist approach (where loyalty is an attitude; a psychological commitment) (Odin, Odin, \& ValetteFlorence, 2001). While each approach has its advantages and disadvantages (see Odin, Odin, \& Valette-Florence, 2001), the current study is concerned with brand attitudes, so the determinist definition is the most important fit and remains consistent with POM, credibility, and purchasing 
intentions. Lin and Tsai (2006) found that when customers develop a relationship with a brand, a passion ensues and they are more likely to remain loyal, even when faced with conflicting messages later on. The relationship development is likely done on an attitudinal, psychological level since it is a relationship with a brand as a whole and not necessarily individual representatives of a brand, even if they do influence brand experiences. That said, when a brand is perceived as possessing positive qualities that are considerate of its consumers (POM and credibility), it is logical that these perceptions lead to a stronger 'relationship' with the brand that will develop a loyal attitude. Because of this, the following hypotheses are posed:

H6: Consumers will have more loyal attitudes toward a brand that has more POM.

H7: Consumers will have more loyal attitudes toward a brand that they perceive as being credible.

Odin, Odin, and Valette-Florence (2001) also acknowledged that a key component of loyalty to a brand is a purchasing response, whether that was a behavior (repeated purchasing of a product) or an attitude (the commitment to a purchasing intention). That said, there may be a reciprocal relationship between loyalty and purchasing intention since, by the suggestion of the determinist definition of loyalty, an ongoing and resilient intent to purchase may be perceived as a form of brand loyalty. Taking this into consideration, the following hypothesis is predicted:

H8: A consumer's loyal attitude toward a brand will be positively correlated with her or his purchasing intentions of that brand's products.

Finally, 'self-congruity' refers to "the match between consumers' self-concept (actual self, ideal self, etc.) and the user image (or 'personality') of a given product, brand, store, etc." (Kressmann, Sirgy, Herrmann, Huber, Huber, \& Lee, 2006, p. 955). Self-congruity is guided in part by self-esteem and has been suggested as a major predictor of brand loyalty (Kressmann et 
al., 2006), which flows logically that an individual would have a stronger relationship with a brand that improves or protects their self-esteem, leading to more loyal attitudes of that brand. With this in mind, the final hypothesis is as follows:

H9: Consumers who report a higher self-esteem after exposure to a brand's advertisement will also report higher loyalty attitudes toward the advertised brand than consumers who report a lower self-esteem after the exposure.

This review of the current literature suggests, as represented by research questions and hypotheses illustrated in Figure 1, the presence of a disclaimer on beauty and fashion advertisements can influence self-esteem, perceived organizational morality, and perceived credibility, ultimately influencing purchasing intentions and loyalty attitudes.

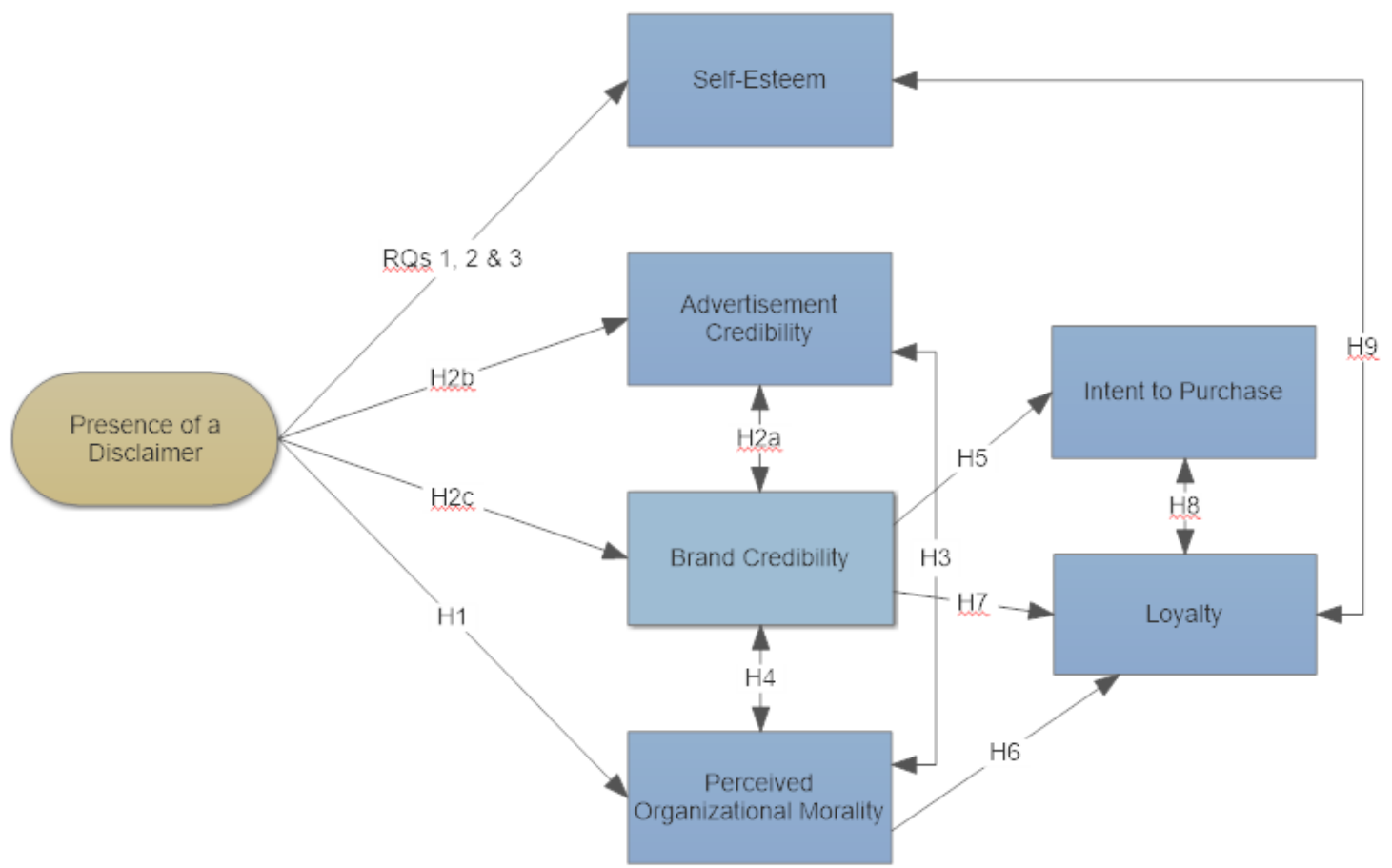

Figure 1: Proposed hypothesis model 


\section{CHAPTER III: METHODS}

\section{Participants}

Participants were recruited from a public Midwestern university. By using a Research Announcement Board in the School of Communication, undergraduate and graduate students enrolled in a communication course were recruited to take a survey. This population included freshmen enrolled in the basic communication course required by all majors, so it was not restricted solely to students studying communication. The average age reported was 20.83 ( $S D=$ 2.43). This was an appropriate age given that Hollister was the brand that was used in the stimulus; Hollister targets 'Gen Z' (Schlossberg, 2016a): those born after 1995 and the generation following the Millennials. While the age group used in this study represents a sample that is transitional between Millennials and Gen Z, it is still fair to suggest that all traditional college students are targeted through the clothing styles, store atmosphere, and discounts exclusive to college students (hollisterco.com, 2017). However, it should also be noted that participants were asked to state a numeric value of how many pairs of Hollister jeans that they currently own, and the results $(M=.84, S D=1.87)$ indicate that this number was very low and frequently zero.

The advertisement stimulus that was used included both a man and a woman in it with the purpose of providing a majority of participants with a model that they can identify with, recalling Hoffner and Buchanan's (2005) suggestion that perceiving even a single similarity, such as gender, with a character may trigger comparison and identification with that character. Forty men and 137 women participated in the study and were randomly assigned among six stimulus conditions. 


\section{Procedure}

The six conditions in this study resulted from a 3 (disclaimer) x2 (model size) factorial design of the independent variables. Once a participant agreed to participate in this study, they were randomly assigned to one of six conditions. After this process had taken place, 29 participants ended up in the "no disclaimer, thin model" condition, 31 participants were placed in the 'presence disclaimer, thin model' condition, 32 participants were assigned to the 'absence disclaimer, thin model' condition, 30 participants were assigned to the 'no disclaimer, average model' condition, 30 participants were placed in the 'presence disclaimer, average model' condition, and 25 participants ended up in the 'absence disclaimer, average model' condition. This distribution is organized by participants' gender identification in the table below:

\begin{tabular}{|l|c|c|c|c|}
\hline \multirow{2}{*}{} & \multicolumn{2}{|c|}{ Thin Body Type } & \multicolumn{2}{c|}{ Average Body Type } \\
\cline { 2 - 5 } & Female & Male & Female & Male \\
\hline No Disclaimer & 24 & 5 & 23 & 7 \\
\hline Presence Disclaimer & 22 & 9 & 23 & 7 \\
\hline Absence Disclaimer & 25 & 7 & 20 & 5 \\
\hline
\end{tabular}

Once assigned to a condition, participants were first exposed to an online consent form and could not proceed without acknowledging and agreeing to it electronically. From here, participants were given directions that they would be evaluating a company's online magazine product advertisement for jeans and that they will be asked to answer a series of questions following exposure to the advertisement. Jeans were the product chosen since they are a more generic product that both men and women purchase. Hollister was chosen as the brand based on a survey taken by 25 participants of similar demographics to those that the survey was available to. They were asked to rate 20 jean brands on a scale from 1-10, 1 being 'really dislike' and 10 being 'really like.' Hollister jeans received a mean score of $M=6.04$, which as near the middle, but also received the highest standard deviation of $S D=2.30$, allowing for the most variance of 
opinion. The Hollister brand also suited the visual aspects of the advertisement with the beach theme.

Once they understood their duties, the next screen revealed the advertisement (with the assigned condition - see Appendix A) for as long as they felt appropriate. Setting a standard time for stimulus exposure would hinder external validity since real magazine advertisements are viewed at the consumer's discretion. From here, participants then answered a series of survey questions and were thanked for their time.

\section{Variables and Measurement}

After exposure to one of the three advertisement manipulations, participants completed a survey addressing self-esteem, POM, credibility, purchasing intention, loyalty, and demographics. The self-esteem measurements were placed after brand loyalty with the intention that a small break between the advertisement exposure and self-esteem measurements would lessen the chance that a participant would assume what the survey was going to be about and alter their responses accordingly.

\section{Images and Disclaimers}

An advertisement was created by piecing together multiple images including models, a background, a brand logo, and a version of the disclaimer (or no disclaimer) (see appendix A). This was the route that was taken because it was important to construct an image that activated only the thought processes that would be measured by the dependent variables. A male and female model were chosen with only part or none of their faces showing and with little to no clothing on aside from the jeans. This topless or bare back concept is not uncommon in real jean advertisements, but the models chosen allowed for the removal of overly-sexualized positioning of the models and other factors, such as facial expressions and other articles of clothing, from 
influencing the consumer of the image. A beach background was chosen to be consistent with Hollister's true advertising theme and the logo was placed discretely in the corner to allow for identification of the brand without additional text distraction.

Since thinness is an important component of America's social construction of physical attractiveness (Greenwood, 2009; Hoffner, 1996; Hoffner \& Buchanan, 2005; Martin \& Gentry, 1997; Richins, 1991; Sohn, 2009), the models in the advertisement were digitally altered for the 'average model' conditions to be less thin. This also included softening some of the muscle definition that is typically more visible in thin body types. To measure whether or not this manipulation was perceived as resulting in one 'physically attractive, thin' model condition and one 'comparatively less physically attractive, average' model condition, a pretest was conducted where 30 participants were exposed to each condition and were asked to rate the physical attractiveness of the models on a scale from 1-10, 1 being 'very unattractive' and 10 being 'very attractive.' For this check, the Hollister logo, disclaimer, and background were removed to avoid external influences. Half of the participants were exposed to the thin models first, while the other half were exposed to the average models first; this could hopefully account for any potential priming effects (that, at this point in the study, were unwanted). A t-test revealed that the manipulation was successful in creating two distinguishable model body types where the thin models $(M=7.20, S D=2.30)$ were perceived as being more physically attractive than the average models $(M=5.40, S D=4.04), t(54)=3.91, p<.001$. So, the manipulation was successful in creating two levels of physical attractiveness for the models in the advertisement. This manipulation was done to potentially provide additional information on factors that influence how social comparison and priming processes work in relation to disclaimers. 
The text for the two disclaimers were based on previous research. Ultimately, this study compares an advertisement with no disclaimer, a disclaimer stating that there has been editing done to the models in an image, and a disclaimer stating that there has not been editing done to the models in an image. While this type of comparison has not yet been done in previous research, the verbiage for the two present disclaimers were modified from Ata, Thompson, and Small (2013) and Tiggemann, Slater, and Smyth (2013). For the disclaimers to be as similar as possible, they each had a large label and smaller subtext. Similar to a previous study, the disclaimer stating the absence of any digital manipulation stated, "Retouch Free Zone: the models in this image have not been digitally altered" (Tiggemann, Slater, \& Smyth, 2013, p. 2). The disclaimer that stated the presence of digital manipulation, then, stated, "Warning: the models in this image have been digitally altered." While the 'warning' label has been used in previous research to address more behavioral or safety responses by an advertisement's consumer, Ata, Thompson, and Small (2013) explain that warning labels and disclaimers convey similar disclosures that are inconsistent with an advertisement. Both types of disclaimers were placed in the bottom-left of the advertisement where there was space away from the models and without obstructing any other crucial pieces of the image.

\section{Self-esteem Measures}

Three different scales were used to capture a range of potential effects on self-esteem and social comparison. The first was the State Appearance Comparison scale developed by Tiggemann and McGill (2004). This three-item scale was constructed to "assess the amount of actual appearance processing and comparison in which participates engage" (Tiggemann \& McGill, 2004, p. 30). The questions were minimally adjusted for clarity (changing the more general 'magazines' to a more specific 'advertisement' target) and addressed internal thought processes such as, 'how 
much did you think about your appearance when viewing this advertisement" (see Appendix B). The State Appearance Comparison scale uses a 7-point Likert-type measurement with anchors of 1, 'no thought/no comparison,' and 7, 'a lot of thought/a lot of comparison,' and yielded a high internal reliability $(\alpha=.91)$. This was an important measurement to include for self-esteem and social comparison since participants may be able to more comfortably identify broad thoughts about appearance comparisons, even if they may feel less comfortable about disclosing more specific thoughts and emotions related to their personal self-esteem or body image.

The second self-esteem measurement was the Physical Appearance State Anxiety scale which asked participants to rate their current level of anxiety about a variety of body parts (Reed, Thompson, Brannick, \& Sacco, 1991). The Likert-type scale asks participants to rate their current level of anxiousness from 1, 'not at all,' to 5, 'exceptionally so,' on 15 body parts; about half of these body parts are weight-conscious (thighs, stomach, muscle tone, etc.) and the other half are not (ears, lips, forehead, etc.) (see Appendix C). Similarly to the State Appearance Comparison scale, this scale is designed to capture responses to experimental manipulations, even if these are only temporary disturbances (Reed et al., 1991) which makes the scale appropriate for the state, rather than trait, appearance-specific personal self-esteem that the current study is concerned with. With exposure to individual advertisements being a quickmoving and constantly-changing environment, these responses still carry importance and may be related to priming effects. The scale also has high a high range of internal reliability $(\alpha=.82-.92)$.

The Physical Appearance State Anxiety scale is not as closely linked to social comparison theory as the State Appearance Comparison scale or Wishful Identification scale discussed next, but instead it is more closely serves as a self-esteem measure. Many studies have observed a strong, inverse relationship between measurements of self-esteem and anxiety 
(Byrne, 2000; Greenberg, Solomon, Pyszczynski, Rosenblatt, Burling, Lyon, Simon, \& Pinel, 1992; Kostanski \& Gullone, 1998). Greenberg et al. (1992) provides one explanation for this relationship being that self-esteem serves as a protective buffer against anxiety that results from various types of threats. When self-esteem is increased or maintained, it serves as a protection from anxious feelings, but when there is a threat to one's self-esteem, such as an upwardcomparison with a physically attractive model, this threat actually produces anxiety. A second explanation is that self-esteem functions as a sociometer and is an output of perceived social inclusion; any shortcoming that could result in social exclusion (unattractiveness) will lead to feelings of anxiety (Leary, 1990; Leary, Tambor, Terdal, \& Downs, 1995). Either of these explanations provides justification for an anxiety measure to be appropriate in assessing selfesteem, since these concepts are often closely associated with each other when measured (Leary et al., 1995). Therefore, the anxiety measure was used as an inverse measure of self-esteem.

The final three self-esteem survey questions came from the Wishful Identification scale (Hoffner, 1996). This measurement identifies how different the consumer feels he or she is from the people within a media message as well as how much he or she desires to be more like those people (see Appendix D). This measurement, then, helps to identify a distance between a perceived actual-self and ideal-self that may encourage upward-comparison. The scale was adjusted slightly for clarity to address the models in the advertisements, rather than 'characters,' with hope that this adjustment will not affect the previously measured internal reliability $(\alpha=.80)$. These identification and comparison perspectives are more concerned with the short-term effects of advertisements, which continues to follow the appropriate pattern for state self-esteem measures. 


\section{POM Measure}

Ellemers et al. (2011) adapted a group morality scale (Leach, Ellemers, \& Barreto, 2007) to inquire about the extent an employee of a company believed their organization to be honest, sincere, and trustworthy ( $\alpha=.94)$. Leach, Ellemers, and Barreto's (2007) original scale asked participants to indicate the importance of these three qualities to their specified group. The current study used the same original 7-point scale anchored by 1 (not very important) and 7 (very important) to measure how important participants perceived the traits of honesty, sincerity, and trustworthiness as being to the Hollister brand (see Appendix E). Since only the perceptual angle was changed from group members/employees to consumers of a brand while the conceptual measurement for morality was unchanged, this remained a reliable measure for the concept.

\section{Advertisement and Brand Credibility Measure}

MacKenzie and Lutz (1989) developed a scale measuring advertisement credibility, advertiser credibility, and advertising credibility using three 7-point semantic differential items for each (convincing/unconvincing, believable/unbelievable, biased/unbiased; $\alpha=.71-.82$ ) (see Appendix F). This allows for separate measurements for the perceived credibility of the individual advertisement and for the brand itself, but it also measures an individual's perceptions of advertising in general. With this additional bit of information, the measured credibility of the advertisement participants are exposed to in this study can be compared with the 'resting perceived credibility' of advertisements in general to see if this advertisement is relatively lower, similar or higher.

\section{Purchasing Intention Measure}

Purchasing intention was measured using Dodds, Monroe, and Grewal's (1991) scale that measured a consumer's 'willingness to buy' attitude $(\alpha=.96-.97)$. The scale was adjusted slightly 
by excluding one question since the study was interested in the effects of price on willingness to buy, which is irrelevant to the current study, and by inserting Hollister's jeans as the target of the questions for clarity purposes. The items included statements like, 'if I were to buy jeans, I would consider buying Hollister jeans' (see Appendix G). The scale resulted in a four item 7point Likert-type scale with 1 being 'very low' and 7 being 'very high.'

\section{Loyalty Attitude Measures}

Loyalty was measured using a 'loyalty intentions' scale to measure an attitude that suggested an individual could see her- or himself being loyal to this brand in the future (Harris \& Ezeh, 2008). This study chose to use this measurement of loyalty to account for any participants that did not have any loyalty to Hollister prior to the study, but may have been influenced by the exposure to the advertisement. The scale was originally developed in reference to restaurantexperience and were modified to reference jeans and Hollister, but since none of these questions were restaurant-specific (e.g., 'will you say positive things about this restaurant to other people' was changed to 'will you say positive things about these jeans to other people'), the adjustments were not presumed to influence the reliability of the scale, however it was recalculated and ended

up being (...) The scale includes six items, phrased in future-tense, with 7-point Likert-type answers, 1 being 'very likely’ and 7 being 'very unlikely' (see Appendix H).

\section{Demographics}

Demographics were collected last with the intention of avoiding participant fatigue during the dependent variable measurements. Demographic information included age, gender, ethnicity, and college major. Participants were also asked if they have ever and currently do own a pair of jeans from Hollister since experience could be a key indicator of some attitude selfreports (see Appendix I). 


\section{CHAPTER IV: RESULTS}

\section{Self-Esteem}

While all three measurements (State Appearance Comparison Scale, Physical Appearance State Anxiety Scale, and Wishful Identification Scale) are considered together for self-esteem effects in this study, they are still different enough that if not all of them receive support in the expected direction, there are three separate cognitive processes taking place. Thus, it is possible to break results down into more specific comparative and self-esteem influences. For each scale, items were averaged together to create a single, composite score for each participant. For the PASAS scale, an additional average was found specifically for the weight-related items (overweight, thighs, buttocks, hips, stomach, legs, waist, muscle tone) and for the non-weightrelated items (ears, lips, wrists, hands, forehead, neck, feet), as these have been observed together and separately in previous research (Reed et al., 1991).

Cronbach's alphas were calculated to confirm the reliability of all survey scales. The three items used to measure physical comparison were highly reliable ( $\alpha=.87$ ), as were the 15 overall PASAS measures ( $\alpha=.91)$, the eight weight-related PASAS measures $(\alpha=.91)$, the seven non-weight-related PASAS measures $(\alpha=.89)$, and the three items used to measure wishful identification $(\alpha=.71)$.

In regard to RQ1, an independent-samples t-test was conducted to measure a viewer's physical appearance comparison with an advertisement model between conditions with and without a disclaimer. There was not a significant difference in the scores with the presence of a disclaimer $(M=4.03, S D=1.68)$ and the absence of a disclaimer $(M=4.05, S D=1.66) ; t(175)$ $=.06, p=.885$. This finding suggests for RQ1 that the presence of a disclaimer has no effect on a consumer's physical comparison with advertisement models. 
The second 'self-esteem' component that was measured was wishful identification. An independent-samples t-test was used to analyze the presence of a disclaimer's influence on wishful identification with the advertisement's models. No significant difference of wishful identification was found $(t(175)=.28, p=.401)$ between participants who saw a disclaimer $(M=$ $2.65, S D=.87)$ and those who did not see a disclaimer $(M=2.61, S D=.87)$. This suggests for RQ2 that the presence of a disclaimer also does not impact one's wishful identification with advertisement models.

Finally, three additional independent-samples t-tests were run to compare participants' reported physical appearance state anxiety between conditions with and without a disclaimer. Means from this scale were interpreted inversely compared to the other scales used in this study, where a low mean score indicated low anxiety and high self-esteem. The first t-test used the overall averaged score from all 15 body parts and did not find a significant difference $(t(175)=$ $.41, p=.613$ ) between the reported anxiety of those exposed to an advertisement with a disclaimer $(M=2.03, S D=.77)$ and those without a disclaimer $(M=2.08, S D=.70)$. The second t-test observed the weight-related score exclusively and also did not find a significant difference in anxiety $(t(175)=.28, p=.249)$ between those who saw a disclaimer $(M=2.58, S D$ $=1.02)$ and those who $\operatorname{did}$ not $(M=2.63, S D=.94)$. Finally, a last independent-samples t-test was used to measure the presence of a disclaimer's effect on non-weight related physical characteristics. This test showed no significant difference between participants that saw a disclaimer $(M=1.40, S D=.70)$ and participants who did not see a disclaimer $(M=1.45, S D=$ $.65) ; t(175)=.469, p=.613)$. Overall, these findings suggest for RQ3 that the presence of a disclaimer on an advertisement has no influence on an individual's overall and weight-related physical appearance anxiety compared to advertisements with no disclaimer. 


\section{Perceived Organizational Morality.}

The three questions that were used to measure POM were averaged together for each participant to create one composite score $(\alpha=.97)$. An independent-samples t-test was run to find how the presence of a disclaimer impacts a consumer's POM toward the advertisement's brand. Participants who were exposed to advertisements with a disclaimer reported a higher $(M=$ $3.20, S D=1.81)$ POM score than those who were not $(M=2.75, S D=1.49), t(175)=1.77, p=$ .026, supporting H1. This finding suggests that the implementation of a disclaimer does increase a consumer's POM toward a brand.

\section{Credibility}

The three questions referring to 'advertisement credibility' were averaged together for a single score, as were the three questions referring to 'advertiser credibility,' which in this case is our brand credibility. When testing the reliability of these scales, both scales were relatively unreliable ( $\alpha=.40$ and $\alpha=.57$, respectively), but with the omission of the "biased/unbiased" measure, reliability was greatly improved. Therefore, advertisement credibility was measured using two semantic differential items of "convincing/unconvincing" and "believable/unbelievable" ( $\alpha=.79)$, while brand credibility also was measured with these two semantic differential items $(\alpha=.87)$. Pearson's product-movement correlational analysis was then used to examine the relationship between the reported perceived advertisement credibility and perceived brand credibility. Results indicated a moderate, positive relationship between these measures $(r(173)=.605, p<.001)$, supporting H2a.

An independent-samples t-test was used to measure the effect of a disclaimer on the advertisement's perceived credibility. The test found significant differences $(t(174)=1.60, p=$ $.040)$ between participants who were exposed to a disclaimer on the advertisement $(M=4.26, S D$ 
$=1.54)$ and those who were not $(M=4.61, S D=1.26)$. While the significant difference between these conditions was small, it occurred in the opposite direction that $\mathrm{H} 2 \mathrm{~b}$ predicted where the presence of a disclaimer actually decreased the perceived credibility of the advertisement, thus rejecting $\mathrm{H} 2 \mathrm{~b}$. A t-test was also conducted to measure a disclaimer's effect on the perceived brand credibility. Findings indicated that participants who saw a disclaimer on the advertisement did not significantly perceive the brand as being more credible $(M=4.47, S D=1.61)$ than those who did not see a disclaimer $(M=4.81, S D=1.54) ; t(172)=1.36, p=.609$. This data leaves H2c without support.

$\mathrm{H} 3$ and $\mathrm{H} 4$ predicted that advertisement credibility and brand credibility, respectively, would each be positively correlated with POM. Pearson's r was implemented to examine these relationships. Findings did not indicate a relationship between perceived advertisement credibility and POM $(r(175)=-.14, p=.071)$, but they did find a significant relationship between perceived brand credibility and POM $(r(174)=-.215, p=.004)$, though it was in the opposite direction than was anticipated. These results failed to support both $\mathrm{H} 3$ and $\mathrm{H} 4$, but suggest an inverse relationship between brand credibility and POM.

\section{Purchasing Intentions}

The items on the purchasing intentions scale were averaged together to create a single score for each participant $(\alpha=.98)$. A linear regression analysis was performed to test if the perceived credibility of a brand significantly predicted a consumer's reported purchasing intentions of products from that brand. The analysis revealed brand credibility was a significant prediction of purchasing intention, $F(1,172)=24.52, p<.001, R^{2}=.13$, where brand credibility is inversely related with $12 \%$ of the variance in purchasing intentions $(\beta=-.35)$. Therefore, H5 was supported. 


\section{Loyalty}

The six survey questions that measured loyalty were averaged together for a single composite score for each participant $(\alpha=.94)$. A standard multiple regression analysis was performed for this dependent variable (loyalty) and the independent variables from H6 and H7 (POM and brand credibility, respectively). The regression analysis revealed that these variables significantly predicted a loyalty attitude $(F(2,173)=16.99, p<.001)$, and $R^{2}=.17$. Together, the two independent variables predicted about $20 \%$ of the loyalty attitude variation, with POM positively predicting about $9 \%(\beta=.24)$ and brand credibility negatively predicting $11 \%(\beta=-.28)$. Thus, H6 was supported, but $\mathrm{H} 7$ received results in the opposite direction.

$\mathrm{H} 8$ predicted that loyalty attitudes and purchasing intentions would be positively correlated. To test this hypothesis, Pearson's correlational analysis was used. Findings indicated a strong, positive relationship between these two measures $(r(175)=.87, p<.001)$, providing support for $\mathrm{H} 8$.

Finally, the overall PASAS score was used to represent self-esteem for H9's expectation that it would positively predict loyalty attitudes. A linear regression analysis was conducted with self-esteem being the independent variable and loyalty being the dependent variable. The analysis revealed that self-esteem did not significantly predict the reporting of loyalty attitudes $\left(F(1,175)=2.81, p=.095, R^{2}=.02\right)$ and $\mathrm{H} 9$ was therefore rejected

\section{Post-hoc Analysis}

To more specifically investigate the influence of the different types of disclaimers and different model body types on the study's findings, a variety of additional analyses were conducted taking these manipulations into consideration. The four dependent variables that were predicted by the hypothesis model to be directly influenced by the advertisement itself (based on three disclaimer 
conditions and two body types) were self-esteem, advertisement credibility, brand credibility, and POM.

Although the hypotheses were only interested in observing the differences between advertisements with and without a disclaimer, investigation of the influence of disclaimer types is also merited. The only significant difference that was found when specifically comparing POM scores between the no disclaimer conditions $(M=2.76, S D=.15)$ and the 'presence' disclaimer conditions $(M=3.23, S D=1.93)$, which very closely mirrored the findings in $\mathrm{H} 1$, where the disclaimer significantly improved the POM score $(t(118)=1.49, p=.022)$. Since there were no other significant differences between the no disclaimer, presence disclaimer, and absence disclaimer conditions, it does not appear that disclaimers truly improve one's selfesteem, perceived credibility of the advertisement, or the perceived credibility of the brand, since the original hypotheses tests also failed to support any of these notions.

The current study also wanted to dive deeper into the impact of different model body types on these four variables (self-esteem, POM, advertisement credibility, and brand credibility). Here, significant differences were observed for self-esteem and POM. The total PASAS score alone was used to inversely measure self-esteem, since it was strongly correlated with both the weight-related portion of the scale $(r(177)=.93, p<.001)$ and the non-weightrelated portion of the scale $(r(177)=.79, p<.001)$, making it a representative single measure of anxiety as a whole. With the overall PASAS score inversely representing self-esteem, those who were exposed to average-sized models reported slightly higher anxiety scores $(M=2.10, S D=$ $.87)$, indicating lower self-esteem, than those who were exposed to thin models $(M=2.00, S D=$ $.61), t(175)=.912, p=.004$. However, participants that viewed average-sized models reported higher POM scores $(M=3.50, S D=1.82)$ than participants that saw thin models $(M=2.63, S D$ 
$=1.51), t(175)=.34, p=.005$. While these findings echo the previous positive impacts of disclaimers on POM, they also do find interesting results where those who were exposed to the average models were actually more anxious about their bodies, or had lower self-esteem, than those who saw a thin-ideal model.

Although no interaction effects were found to be significant for the disclaimer types and body types in the advertisements, the current study wanted to further investigate POM. Since it was found to be positively influenced by disclaimers and average body types, as well as to be a positive influencer of loyalty attitudes, an additional linear regression was run to see if POM also influences one's purchasing intention, the other desirable organizational outcome (along with loyalty). A significant relationship was found $\left(F(1,175)=16.95, p<.001, \mathrm{R}^{2}=.09\right)$ where POM predicted about $8 \%$ of a consumer's purchasing intention $(\beta=.30)$. Taken together with the earlier finding of brand credibility's $12 \%$ prediction, these variables are suggested to account for $20 \%$ of purchasing intention's variation.

Finally, after some analysis, the current study recognized the relationship between comparison with advertisement models and self-esteem, as indicated again by the inverse relationship with the overall PASAS score, was another important relationship to explore. A correlational test was conducted to further understand the fluctuation of these measures, and a significant, positive correlation was found, $r(177)=.369, p<.001$. This relationship suggests that participants who compared themselves more to the models in the advertisement also had a tendency to report a lower self-esteem score (or a higher physical anxiety score). See Tables 1 and 2 for an overview of descriptive statistics and correlations between variables for this study. 


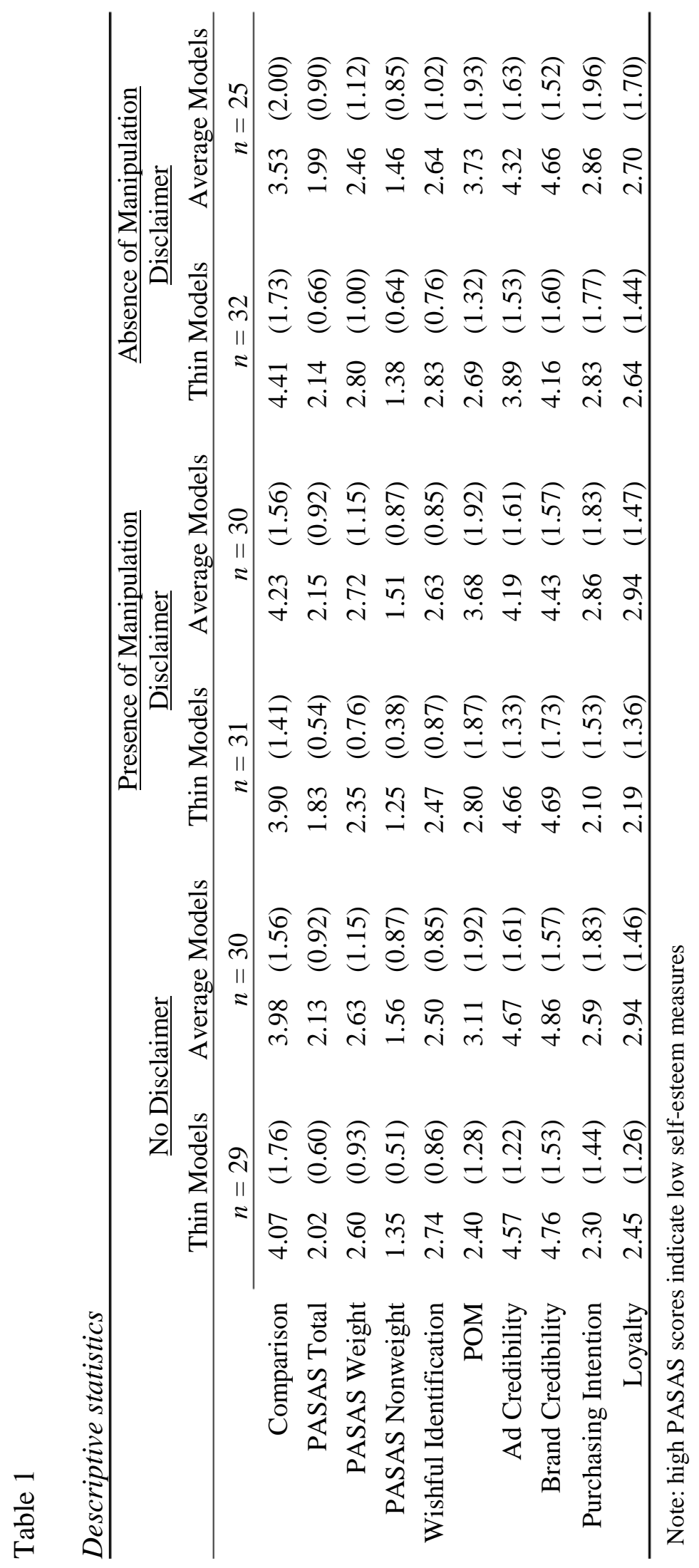




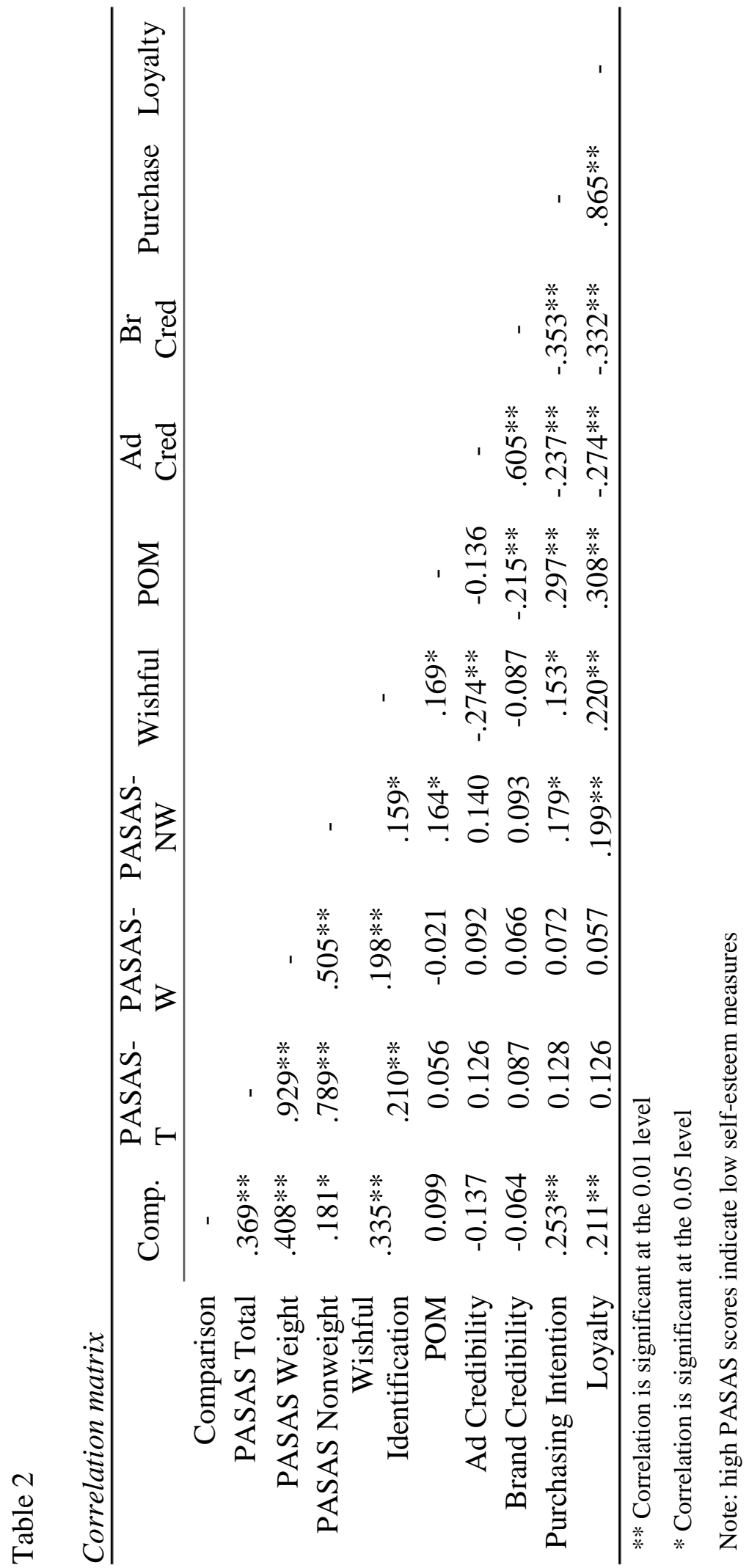




\section{CHAPTER V: DISCUSSION}

This study provides further insight into the processes laid out by social comparison theory and priming effects. This study also contributes additional research to previously conflicting results found in self-esteem studies and suggest a variety of more practical implications for consumers and organizations. While the current study took into account variables that are not always observed in congruence with each other, it suggests that the consideration of consumer well-being and brand benefits should accompany each other in research more often. To review, the presence of a disclaimer did not have any significant effects on any of the self-esteem related measures, but it did decrease advertisement credibility and increase POM. While brand credibility is positively correlated to advertisement credibility, it is negatively correlated with POM. Finally, brand credibility and POM each have significant influences on loyalty as an attitude and purchasing intentions, two variables that are also positively correlated with each other. Finally, average model body types actually resulted in lower reported self-esteem than their thin counterparts, but also increased POM.

\section{Implications for Social Comparison Theory and Priming Effects}

The current study provided important implications for both social comparison theory and priming effects as examined in a mass media/advertising context. While the current study did not find any significant differences in comparison tendencies for disclaimer presence or model body type, overall comparison scores were relatively high, with an average of $M=4.04(S D=1.67)$ on a five-point scale. Further, self-esteem, as indicated by the inverse relationship with the physical appearance state anxiety scale, overall was also high $(M=2.05, S D=.74)$, which indicates a relatively high self-esteem. Self-esteem was significantly lower for average models than thin-ideal models, which may suggest more complicated cognitive processes, in congruence 
with comparison, take place during exposure to advertisement models than a simple, 'that model is more physically attractive than me and that makes me feel bad,' thought process that social comparison theory may predict. The general scores reported in this study suggest that a lot of comparison does take place with advertisement models, but the psychological, self-esteem related processes that follow that comparison warrant further investigation.

Recalling Martin and Gentry's (1997) comparison motive of self-improvement, previous research has suggested that self-improvement may be more likely to take place when one feels that the comparison target is a non-competitor (Lockwood \& Kunda, 1997). Relevant to this study, comparison levels remained relatively steady while self-esteem was lower for those who were exposed to the average model body type, rather than the thin model body type. These findings may suggest that, since those body types are more representative of 'real' people, they may be perceived as more immediate competition than less common, thin-ideal bodies. This social threat, then, encourages more self-evaluation than self-improvement motives when engaging in upward-comparison, thereby negatively influencing self-esteem. Body types and physical attractiveness certainly need further analysis through the consideration of social comparison theory.

Self-enhancement is another motive for comparison where individuals are able to protect their self-esteem through recognition of the unrealistic components of, for example an advertisement model (Martin \& Gentry, 1997). The current study found more support for this being a difficult motive to encourage, since even the blatant statement revealing photo manipulation was not found to lessen comparison with the models. While it seems that a disclaimer was unable to encourage this motive, this study also emphasizes the importance of 
further research on self-enhancement and ways to motivate comparison other than through selfevaluation. This idea also relates to visual literacy, which will be discussed shortly.

Although social comparison theory has been studied through social influence and individual psychology lenses, (Morse \& Gergen, 1970), there may be components of the theory that only work in one sense or another. The motives of self-evaluation, self-improvement, and self-enhancement may lie more in the individual's personality and psychology, rather than outside circumstances surrounding the comparison. This echoes Sohn's (2009) observation that there are many personal forces that influence one's comparison tendencies and further highlights social comparison theory's limitation of not being able to take into account some of the cognitive processes that take place during comparison as well as the difference in perceptions and experiences in individuals and how those dictate comparison consequences.

As for priming effects, Yi's (1990) suggestion that advertisements can be evaluated based on constructs accompanying the advertisement (i.e., disclaimers) does not seem to be the case here in regards to how the advertisement makes people feel about themselves, but it may be a legitimate strategy for organizations to implement to further address brand attitudes. The simultaneous exposure to a disclaimer and an advertisement was not observed as having any type of protective priming effect for physical comparison or self-esteem. Although disclaimers did have some effects on brand attitudes, they may have been seen simply as an additional component of an advertisement, rather than a priming tool. The current study posits that Yi's suggestion may be correct, but that this simultaneous exposure is outside of the realm of priming effects. However, if advertisements in a magazine, for example, worked together and included multiple disclaimers throughout, it may be possible that the disclaimers could compound on each other to prime the latter messages as a reader sifted through the magazine. Priming research may 
need to expand to observe this strategy, alongside research on priming events based on single priming stimuli, to better replicate the saturated bombardment that current media consumers undergo in today's society. Priming effects may be present in this chaos, but priming events and stimuli should be observed in more collective and practical situations.

Finally, the lack of support for disclaimers in this study may simply suggest that priming effects are incapable of weighing out cultivation effects, even temporarily, for certain feelings and circumstances. Cultivation theory, broadly, suggests that long-term, frequent exposure to media messages will result in consumers' beliefs mirroring those that they see in these messages (Gerbner \& Gross, 1976). Since physical attractiveness is such an important, desired characteristic in American society, especially, the accumulation of decades of messages reiterating the feelings of inadequacy might simply overpower the purpose of such a brief, nonaggressive priming attempt such as a disclaimer. Normative discontent may overrule disclaimers' effectiveness, as discussed in the next section, and larger efforts, such as improved education or full campaigns, may be necessary to combat cultivation effects and allow for well-intended priming efforts to be successful.

\section{Photo Disclaimers May Just Be Useless in the World of Advertising}

The culmination of insignificant findings in all three self-esteem related measures does not outright support a protective effect or a boomerang effect of disclaimers on advertisements. One's physical comparison with the models, physical state anxiety, and wishful identification with the models were all unaffected by the exposure to a disclaimer. While the current study did observe these different components of self-esteem separately, it did not provide support for either side of the debate over whether or not disclaimers of photo manipulation help or harm 
consumers. It may be as simple as disclaimers being an insufficient method of trying to protect one's self-esteem, or it may be reflective of normative discontent or low visual literacy.

Tantleff-Dunn, Barnes, and LaRose (2011) described a shift in trait self-esteem, which is likely to influence state self-esteem during advertisement exposure, toward normative discontent: “dissatisfaction with one's weight has become so prevalent among women that feeling negatively about one's appearance is thought to be the 'norm' rather than the exception" (p. 392). Although their findings did not indicate if this feeling also applies to men, its implications would suggest that low self-esteem is a baseline, rather than a response to a stimulus. Therefore, advertisements cannot improve self-esteem, but rather they may lessen the negative impacts of their images. However, while the current study did find high levels of physical comparison to the advertisement models, the overall reported physical state anxiety measures were low (indicating high self-esteem), and the average wishful identification score was low to moderate $(M=2.64$, $S D=.87$ ), suggesting that high comparison did not necessarily result in a desire to be more like the models. These findings suggest a complex psychological process is taking place in relation to self-esteem and its influencers and the exposure to a single disclaimer may not have enough impact to sway this process.

\section{The Continuous Importance of Visual Literacy}

While disclaimers may not be able to directly protect self-esteem, or more largely body image, they still may serve a purpose toward improving visual literacy. While media literacy refers to one's skill in analyzing and evaluating media messages (Livingstone, 2004), visual literacy, more specifically, refers to one's necessity to be "alert to visual messages and critically read or view images as the language of the messages," where visual literacy is a culturallyspecific language (Stokes, 2002, p. 12). Groesz, Levine, and Murnen (2002) suggested that being 
more media literate can help prevent the negative influences that many media messages have on body image and self-esteem, so being visually literate is likely an important component of this as well.

Ongoing education of consumers may be a necessary practice to prepare them for the potentially negative consequences of media consumption (Harrison \& Hefner, 2014), and while systematic interventions and programs may be necessary to improve media and visual literacy (for a more complete overview of specific media literacy efforts, see Kellner \& Share, 2005), disclaimers may work alongside these longitudinal efforts to further supplement these improvements (Veldhuis, Konijn, \& Seidell, 2014). If disclaimers can help to improve society's media and visual literacy, they may also indirectly help to contribute to the desirable consequences of these improvements, such as the protection of body image and self-esteem, through some of the assumptions proposed by social cognitive theory (Bandura, 1997). Social cognitive theory suggests that an individual's knowledge and attitudes are largely influenced social structures, both through personal interactions and media consumption. Social structures are "created by human activity" to "organize, guide, and regulate human affairs in given domains by authorized rules and sanctions" that "impose constraints and provide resources for personal development" (Bandura, 1997, p. 6). The emphasis here is that disclaimers and pooling of other resources or implementation of other strategies to improve visual literacy could help to educate society as a whole and equip them with the knowledge to consume ever-present media messages more critically and, ultimately, more safely. As Bandura (1997) stated, "personal and social change are complementary rather than rival approaches to improving the quality of life" (p. 7). 


\section{Model Body Types are a Strategic Organizational Tool}

The current study also sought to examine what effects varying model body types had on self-esteem and brand attitudes. The results indicated a significantly lower self-esteem and higher POM score for participants that were exposed to the average body type rather than the more common, thin body type. As for self-esteem, the only significant difference was also found in the physical state anxiety measurement, in the direction opposite of what one may expect, with no significant differences in physical comparison or wishful identification. The findings for selfesteem conflict with the idea that a more average model will relieve some of the negative consequences of upward comparison, so further research should be done to really parse through this relationship since it seems to be assumed often with little empirical data for support.

There was no significant difference in perceived advertisement credibility, perceived brand credibility, purchasing intention, or loyalty attitudes between the two body types. While additional research to echo these findings is necessary, this study provides organizations with data that suggest it may be unnecessary to select thin-ideal models to represent their brands. Although the average models in the advertisement still may be more attractive than a 'truly average' person, since they are indeed models, it may widen the pool of models that organizations can employ and ultimately eliminate some of the competition that leads to more expensive, professional, successful models for advertisements. Widening the hiring pool for organizations may ultimately save them money on the internal front without compromising product sales. Further, some companies have actually benefitted from the inclusion of more diverse model body types, though the focus here is specific to women.

Two notable companies, Dove and Aerie, have already gotten a jump start on the inclusion of more diverse body types and exposures in their advertisements. While the current 
study did not find a difference, Dove's Campaign for Real Beauty launched in 2004 and included plus-sized female models as large as size 12 in their underwear in advertisements for Dove's beauty products, mainly lotions and soaps (Corbett, 2006). In the years since, Dove has been acclaimed and criticized for its variety of messages associated with the campaign. In the first 10 years of the campaign, Dove's annual sales increased from $\$ 2.5$ billion to $\$ 4$ billion and the company was even recognized as being one of the best advertising campaigns in the $21^{\text {st }}$ century (Chumsky, 2015). However, though Dove as a brand has reaped the benefits of this campaign, the authenticity and motives of its employees behind the campaign have been questioned every step of the way. One common foundation critics stand on is that Dove's parent company is Unilever, which also owns Slimfast and Axe, even if these brands act independently of each other (Bahadur, 2014). Others have voiced issues that the 'larger' models still look airbrushed and do not truly represent the average size-14 American woman body type (Corbett, 2006); even if they did, the base fact that Dove sells products such as cellulite cream and firming lotions seem to suggest that they are using women's insecurities to increase profits (Bahadur, 2014). Overall, Dove has run a successful campaign thus far and continues to find new tactics to address body image in ways that do not relate as closely to their products that may help to improve their POM to more effectively integrate diverse model body types. However, much like the current study, the outcomes of this 'groundbreaking' campaign on both consumers and Dove as a brand warrants further scholarly research.

Aerie, an intimates-only branch off of American Eagle, took a slightly different approach to tackling body image and self-esteem by abandoning photo-editing from their advertisements entirely beginning in 2014 (Schlossberg, 2016). While the advertising ploy is still relatively young compared to that of Dove's, it has been met with overwhelmingly positive feedback as 
well as a 32\% increase in sales as of 2016 (Torgerson, 2016). They took their movement a step further by even including 'regular women,' or 'non-models' in their advertisements by casting their own staff members, bloggers, designers, and customers completely untouched by photoediting software (Rodulfo, 2016). Whether it is the seemingly genuine and empowering interviews with Aerie's president Jennifer Foyle and Aerie models, a younger target audience, or the slightly different product that Aerie is selling in the retail sector, compared to brands like Dove, the brand is perceived as competing with powerhouse Victoria's Secret in the lingerie market, even with about $1 / 16^{\text {th }}$ of the annual sales (Schlossberg, 2016b). Aerie and Dove may be two companies that public relation departments of more brands should observe more closely to see how to include POM and different models to connect with customers and increase profit through more mutually-beneficial, humanely-ethical means. The success and popularity of these 'pilot-campaigns' may also increase pressure on other companies, especially those competing in

these particular industries, to acknowledge and act in accordance with this movement to maintain or build a stronger reputation and relationship with their customers.

\section{POM as a New, Important Brand Consideration}

An additional contribution of the current study is its introduction of the perceived organizational morality concept. Results supported the idea that the inclusion of some type of photo manipulation disclaimer on an advertisement (be it a disclaimer stating the presence or absence of this manipulation) yielded higher consumer POM scores. POM also lead to increased purchasing intentions and loyalty attitudes, providing a link between disclaimers and these potential behaviors. POM was found to predict $9 \%$ of the variance in loyalty and $8 \%$ of the variance in purchasing intention. Especially from an organizational perspective, these 
percentages could have a large impact on net outcomes. Thus, POM may be a variable that brands should consider and investigate more closely as they develop.

Although it has not been labeled or addressed as explicitly in research yet, literature does show that organizations in other countries such as Brazil, Australia, and Israel have implemented a variety of strategies to address body image and self-esteem in media messages, which may in part be to increase their POM. For example, the United Kingdom banned digital manipulation of photographs in advertisements targeting children under the age of 16 and require other advertisements to include a label in accordance with a system that rates how much retouching has been done (O’Neil, 2014). France has a similar label requirement and has also made it illegal to glorify extreme thinness (O’Neil, 2014). Since these are government-mandated regulations, it is uncertain if the organizations themselves that abide by these rules are seen as being any more moral, but United States organizations may look to some of these international implementations for alternative ideas, outside of disclaimers, to increase their POM.

The current study found that brand credibility was strongly and positively correlated with advertisement credibility. This relationship makes practical sense since individual advertisements are elements that build toward pieces of a brand's overall credibility, whereas a brand's credibility likely influences the way we anticipate and perceive the advertisements released from that brand. Since disclaimers had a significant negative influence on advertisement credibility scores, they may also indirectly have a negative influence on brand credibility.

Brand credibility was the other significant variable in predicting purchasing intentions and loyalty attitudes in this study, however, both of these relationships were in a negative direction. It was unaffected by disclaimers and was actually inversely related to POM, which is a relationship that deserves further investigation. Brand credibility and POM together predicted 
about $20 \%$ of the variance in purchasing intention and loyalty, so if they truly do negatively influence each other as the findings suggest, research would advise organizations to focus more on POM than brand credibility. An increase in POM led to higher loyalty attitudes and purchasing intentions; even if POM efforts decrease brand credibility (i.e., a disclaimer increases POM but decreases advertisement credibility which may lead to decreased brand credibility, too), this decrease, as a piece of a larger set of relationships, still significantly predicts increases in loyalty attitudes and purchasing intentions overall.

There are a few explanations as to why brand credibility and POM are inversely related. It may simply be difficult for a fashion brand, especially, to be seen as being credible and acting morally at the same time. There may be a stereotype that exists in American culture that expects advertisers to be deceiving, which would indicate that maybe it is more of a directional relationship, rather than correlational, where brand credibility is generally low in this industry and makes it difficult for POM to be used effectively. A second explanation may view POM as a component of brand credibility, since it may be an element that influence's a brand's reputation and consumer relationships. For the current study, POM was likely a product of the transparency offered by a disclaimer. Again suggesting a directional relationship, increases in POM through some messages may lead to doubts or questions of other components of an organization, thereby decreasing its overall brand credibility. This relationship has not yet been observed directly in past research and needs to be broken down further for clearer interpretation and understanding. Finally, the relationship between brand credibility and POM may be a result of a larger, more complicated set of relationships at work. In this study, the exposure to a disclaimer lead to increased POM scores and decreased advertisement credibility scores. It may have been the decreased advertisement's credibility that lead to a decrease in brand credibility for conditions 
that had a disclaimer, rather than the increase in POM. While POM and brand credibility fluctuated together, that does not indicate causation between these variables. Along this line of thinking, the presence of a disclaimer, while it does increase POM and seems to indirectly decrease brand credibility, may ultimately contribute to positive attitudes toward loyalty and purchasing a brand's product. The complexity of this relationship would benefit from research using other POM-increasing efforts beyond a disclaimer to add clarity to where these direct and indirect relationships exist.

\section{Limitations and Future Research}

While any experiment will have its limitations, perhaps the greatest contribution of the current study is its preliminary combination of variables that are not typically considered together and its suggestions for future research in the fields of communication, psychology, and marketing. However, the stimulus for the current study may have benefited from further development. The retouching of the image itself to create two different body types as well as the development of disclaimers based solely on the message and less on aesthetics likely limited its apparent legitimacy, especially with disclaimers being a relatively new inclusion for American consumers. Future research should experiment further with model body types, positioning, etc. in a larger variety of brands and products (beyond jeans) as well as testing the placement, size, and physical elements of a disclaimer itself to observe its organizational significance. The current study also only had a single advertisement as a stimulus, which may have not allowed viewers to digest it in a realistic way mimicking their consumption of media advertisements. Future research can create stimuli of multiple pages and images that include a disclaimer to see if the effects become stronger as they accumulate, or researchers may even recruit from populations in 
countries where disclaimers are common to see if they maintain longitudinal effects after their introduction.

While the current study used measures of physical comparison, physical state anxiety, and wishful identification to encompass multiple facets of self-esteem, they may have been too tangential or unique to include under an umbrella of self-esteem measurements. Future research should modify existing self-esteem measures to address appearance-specific state self-esteem more closely, or continue to observe disclaimers' (or other methods') effects on various body image and self-esteem related elements.

Although this study considered both self-esteem on the consumers' end and brand attitudes as benefits for organizations, it failed to consider whether disclaimers improve an individual's visual literacy. During an age of complete saturation in media and visual messages, this may be a skillset that is not only important to observe on its own, but also as a target for improvement through different forms of education. Future research should observe disclaimers' effects on visual literacy as well as a more thorough analysis of visual literacy's effect on body image and self-esteem.

Additionally, future research should further examine the influence of varying model body types on other organizational components aside from credibility, loyalty, and purchasing intentions. It may also be beneficial to note how government-enforced regulations influence POM compared to brand-enforced strategies and in what ways POM is influenced in relation to brands outside of the beauty and fashion advertising industry. The relationship between POM and brand credibility was a surprising one in the current study and should be investigated further to find justifications or contradictions. Finally, the variance in self-esteem measures for the current study was overall low, the way self-esteem may be a product of disclaimers and body 
types or may influence loyalty and purchasing intentions are all relationships that may require further investigation with a more diverse population or with various types of brands.

\section{Conclusion}

This study revealed the importance of studying variables from a range of related fields together to yield more practical and applicable results for companies to communicate more

effectively and morally with their consumers. By considering consequences such as self-esteem alongside strategizing for desirable brand outcomes like loyalty and purchasing, a brand may improve their relationships with customers by acting in a way that is honest and sincerely considerate. The outcome of this interaction is organizational morality, which benefits consumers and brands alike when communicated effectively and perceived correctly. While selfesteem and brand benefits are not typically considered together, it is necessary for the advertising industry to take responsibility for their actions and develop a more mutually beneficial, ethical approach beyond solely increasing profit. 


\section{REFERENCES}

Arroyo, A., Segrin, C., \& Harwood, J. (2014). Appearance-related communication mediates the link between self-objectification and health and well-being outcomes. Human Communication Research, 40, 463-482. doi: 10.1111/hcre.12036

Ata, R. N., Thompson, J. K., \& Small, B. J. (2013). Effects of exposure to thin-ideal media images on body dissatisfaction: Testing the inclusion of a disclaimer versus warning label. Body Image, 10, 472-480. doi: 10.1016/j.bodyim.2013.04.004

Aubrey, J. S. (2006). Effects of sexually objectifying media on self-objectification and body surveillance in undergraduates: Results of a 2-year panel study. Journal of Communication, 56, 366-386. doi: 10.1111/j.1460-2466.2006.00024.x

Aubrey, J. S. (2007). The impact of sexually objectifying media exposure on negative body emotions and sexual self-perceptions: Investigating the mediating role of body selfconsciousness. Mass Communication \& Society, 10, 1-23. doi:

$10.1080 / 15205430701229584$

Aubrey, J. S., Henson, J. R., Hopper, K. M., \& Smith, S. E. (2009). A picture is worth twenty words (about the self): Testing the priming influence of visual sexual objectification on women's self-objectification. Communication Research Reports, 26, 271-284. doi: $10.1080 / 08824090903293551$

Bahadur, N. (2014). Dove 'Real Beauty' campaign turns 10: How a brand tried to change the conversation about female beauty. The Huffington Post. Retrieved from http://www.huffingtonpost.com/2014/01/21/dove-real-beauty-campaign-turns10_n_4575940.html 
Bandura, A. (1997). Self-efficacy: The exercise of control. New York, NY: W. H. Freeman and Company.

Bissell, K. L. (2006). Skinny like you: Visual literacy, digital manipulation, and young women's drive to be thin. Simile, 6. doi: 10.3138/sim.6.1.002

Bissell, K. \& Rask, A. (2010). Real women on real beauty: Self-discrepancy, internalization of the thin ideal, and perceptions of attractiveness and thinness in Dove's Campaign for Real Beauty. International Journal of Advertising, 29(4), 643-668. doi: $10.2501 / \mathrm{S} 0265048710201385$

Blair, J. D., Stephenson, J. D., Hill, K. L., \& Green, J. S. (2006). Ethics in advertising: Sex sells, but should it? Journal of Legal, Ethical, and Regulatory Issues, 9, 109-118. Retrieved from http://search.proquest.com/openview/ff088426e89238d5122b56fd97d3b285/1?pqorigsite $=$ gscholar $\& \mathrm{cbl}=38868$

Boush, D. M. (1993). How advertising slogans can prime evaluations of brand extensions. Psychology \& Marketing, 10, 67-78. doi: 10.1002/mar.4220100106

Bower, A. B. (2001). Highly attractive models in advertising and the women who loathe them: The implications of negative affect for spokesperson effectiveness. Journal of Advertising, 30(3), 51-63. doi: 10.1080/00913367.2001.10673645

Breckler, S. J. \& Greenwald, A. G. (1986). Motivational facets of the self. R. M. Sorrentino \& E. T. Higgins (Eds.), Handbook of motivation and cognition: Foundations of social behavior (pp. 145-164). New York, NY: Guilford Press.

Brown, S. P. \& Stayman, D. M. (1992). Antecedents and consequences of attitude toward the ad: A meta-analysis. Journal of Consumer Research, 19, 34-51. doi: 10.1086/209284 
Byrne, B. (2000). Relationships between anxiety, fear, self-esteem, and coping strategies in adolescence. Adolescence, 35, 201-216.

Carroll, A. B. (1991). The pyramid of corporate social responsibility: Toward the moral management of organizational stakeholders. Business Horizons, 39-48. doi: 10.1016/0007-6813(91)90005-G

Chumsky, S. (2015, April 15). Why Dove's 'Choose Beautiful' campaign sparked a backlash. Fortune.com. Retrieved April 13, 2017 from http://fortune.com/2015/04/15/why-doveschoose-beautiful-campaign-sparked-a-backlash/

Clay, D., Vignoles, V. L., \& Dittmar, H. (2005). Body image and self-esteem among adolescent girls: Testing the influence of sociocultural factors. Journal of Research on Adolescence, 15(4), 451-477. doi: 10.111/j.1532-7795.2005.00107.x

Collins, R. L. (1996). For better or worse: The impact of upward social comparison on selfevaluations. Psychological Bulletin, 119, 51-69. doi: 10.1037/0033-2909.119.1.51

Corbett, R. (2006). Dove's larger models spur sales and attention. Women's News. Retrieved from http://womensenews.org/2006/01/doves-larger-models-spur-sales-and-attention/

Cotte, J., Coulter, R. A., \& Moore, M. (2005). Enhancing or disrupting guilt: The role of ad credibility and perceived manipulative intent. Journal of Business Research, 58, 361-368. doi: 10.1016/S0148-2963(03)00102-4

Dickinson-Delaporte, S., Ford, J. B., \& Gill, D. (2014). Model looks, motives, and affective outcomes. Journalism \& Mass Communication Quarterly, 9, 357-374. doi:

$10.1177 / 1077699014527454$ 
Dodds, W. B., Monroe, K. B., \& Grewal, D. (1991). Effects of price, brand, and store information on buyer's product evaluations. Journal of Marketing Research, 28, 307-319. doi: $10.2307 / 3172866$

Ellemers, N., Kingma, L., van de Burgt, J., \& Barreto, M. (2011). Corporate social responsibility as a source of organizational morality, employee commitment and satisfaction. Journal of Organizational Moral Psychology, 97-124. doi: 10.1016/j.riob.2012.11.002

Federal Trade Commission. (n.d.) Advertising and Marketing. Retrieved from https://www.ftc.gov/tips-advice/business-center/advertising-and-marketing

Festinger, L. (1954). A theory of social comparison processes. Human Relations, 7, 117-140. doi: $10.1177 / 001872675400700202$

Flanagin, A. J. \& Metzger, M. J. (2007). The role of site features, user attributes, and information verification behaviors on the perceived credibility of web-based information. New Media and Society, 9, 319-342. doi: 10.1177/1461444807075015

Forehand, M. R. \& Deshpande, R. (2001). What we see makes us who we are: Priming ethnic self-awareness and advertising response. Journal of Marketing Research, 38(3), 336-348. doi: $10.1509 / j m k r .38 .3 .336 .18871$

Fredrickson, B. L. \& Roberts, T. (1997). Objectification theory: Toward understanding women's lived experiences and mental health risks. Psychology of Women Quarterly, 21, 173-206. doi: 10.1111/j.1471-6402.1997.tb00108.x

Gerbner, G. \& Gross, L. (1976). Living with television: The violence profile. Journal of Communication, 26, 172-199. doi: 10.1111/j.1460-2466.1976.tb01397.x 
Goidel, R. K., Shields, T. G., \& Peffley, M. (1997). Priming theory and RAS models: Toward an integrated perspective of media influence. American Politics Quarterly, 25(3), 287-318. doi: $10.1177 / 1532673 \times 9702500303$

Green, K. C. \& Armstrong, J. S. (2012). Evidence on the effects of mandatory disclaimers in advertising. Journal of Public Policy \& Marketing, 31, 293-304. doi: 10.1509/jppm.12.053

Greenberg, J., Solomon, S., Pyszczynski, T., Rosenblatt, A., Burling, J., Lyon, D., Simon, L., \& Pinel, E. (1992). Why do people need self-esteem? Converging evidence that self-esteem serves an anxiety-buffering function. Journal of Personality and Social Psychology, 63, 913-922. doi: 10.1037/0022-3514.63.6.913

Greenwood, D. (2009). Idealized TV friends and young women's body concerns. Body Image, 6, 97-104. doi: 10.1016/j.bodyim.2008.12.001

Groesz, L. M., Levine, M. P, \& Murnen, S. K. (2002). The effect of experimental presentation of thin media images on body satisfaction: A meta-analytic review. International Journal of Eating Disorders, 31, 1-16. doi: 10.1002/eat.10005

Harris, L. C. \& Ezeh, C. (2006). Servicescape and loyalty intentions: An empirical investigation. European Journal of Marketing, 42, 390-422. doi: 10.1108/3090560810852995

Harrison, K. \& Hefner, V. (2014). Virtually perfect: Image retouching and adolescent body image. Media Psychology, 17, 134-153. doi: 10.1080/15213269.2013.770354

Higgins, E. T. (1987). Self-discrepancy: A theory relating self and affect. Psychological Review, 94(3), 319-340. doi: 10.1037/0033-295X.94.3.319 
Higgins, E. T., Bargh, J. A., \& Lombardi, W. (1985). Nature of priming effects on categorization. Journal of Experimental Psychology: Learning, Memory, and Cognition, 11, 59-69. doi: 10.1037/0278-7393.11.1.59

Hoffner, C. (1996). Children's wishful identification and parasocial interaction with favorite television characters. Journal of Broadcasting \& Electronic Media, 40, 389-402. doi: $10.1080 / 08838159609364360$

Hoffner, C. \& Buchanan, M. (2005). Young adults' wishful identification with television characters: The role of perceived similarity and character attributes. Media Psychology, 7, 325-351. doi: 10.1207/S1532785XMEP0704_2

Iyengar, S., Peters, M. D., \& Kinder, D. R. (2006). Experimental demonstrations of the "not-sominimal" consequences of television news programs. The American Political Science Review, 76, 848-858. doi: 10.1017/S000305540018966X

Jo, E. \& Berkowitz, L. (1994). A priming effect analysis of media influences: An update. J. Bryant \& D. Zillmann (Eds.), Media effects: Advances in theory and research (pp. 4360). Hillside, NJ: Lawrence Erlbaum Associates.

Kellner, D. \& Share, F. (2005). Toward critical media literacy: Core concepts, debates, organizations, and policy. Discourse: Studies in the Cultural Politics of Education, 26, 369-386. doi: 10.1080/01596300500200169

Kostanski, M. \& Gullone, E. (1998). Adolescent body image dissatisfaction: Relationships with self-esteem, anxiety, and depression controlling for body mass. The Journal of Child Psychology and Psychiatry and Allied Disciplines, 39(2), 225-262. 
Kressmann, F., Sirgy, M. J., Herrmann, A., Huber, F., Huber, S., \& Lee, D. (2006). Direct and indirect effects of self-image congruence on brand loyalty. Journal of Business Research, 59, 955-964. doi: 10.1016/j.jbusres.2006.06.001

Leach, C. W., Ellemers, N., \& Barreto, M. (2007). Group virtue: The importance of morality (vs. competence and sociability) in the positive evaluation of in-groups. Journal of Personality and Social Psychology, 93, 234-249. doi: 10.1037/0022-3514.93.2.234

Leary, M. R. (1990). Responses to social exclusion: Social anxiety, jealousy, loneliness, depression, and low self-esteem. Journal of Social and Clinical Psychology, 9(2), 221229. doi: $10.1521 /$ jscp.1990.9.2.221

Leary, M. R. (1999). Making sense of self-esteem. Current Directions in Psychological Science, 8, 32-35. doi: 10.1111/1467-8721.00008

Leary, M. R., Tambor, E. S., Terdal, S. K., \& Downs, D. L. (1995). Self-esteem as an interpersonal monitor: The sociometer hypothesis. Journal of Personality and Social Psychology, 68, 518-530. doi: 10.1037/0022-3514.68.3.518

Lin, C. \& Tsai, C. (2006). Comparisons and advertising: The route from comparisons to effective advertising. Journal of Business and Psychology, 21, 23-44. doi: 10.1007/s10869-0059016-z

Livingstone, S. (2004). Media literacy and the challenge of new information and communication technologies. The Communication Review, 7, 3-14. doi: 10.1080/10714420490280152

Lockwood, P. \& Kunda, Z. (1997). Superstars and me: Predicting the impact of role models on the self. Journal of Personality and Social Psychology, 73, 91-103. doi: 10.1037/00223514.73 .1 .91 
Lombardi, W. J, Higgins, E. T. \& Bargh, J. A. (1987). The role of consciousness in priming effects on categorization: Assimilation versus contrast as a function of awareness of the priming task. Personality and Social Psychology Bulletin, 13, 411-429. doi:

$10.1177 / 0146167287133009$

Lowery, S. E., Kurpius, S. E. R., Befort, C., Blanks, E. H., Sollenberger, S., Bicpon, M. F., Huser, L. (2005). Body image, self-esteem, and health-related behaviors among male and female first year college students. Journal of College Student Development, 46, 612-623. doi: $10.1353 / \operatorname{csd} .2005 .0062$

Lutz, R. J. (1985). Affective and cognitive antecedents of attitude toward the ad: A conceptual framework. L. F. Alwitt \& A. A. Mitchell (Eds): Psychological processes and advertising effects: Theory, research, and application (pp. 45-63). Hillsdale, NJ: Lawrence Erlbaum Associates.

MacKenzie, S. B. \& Lutz, R. J. (1989). An empirical examination of the structural antecedents of attitude toward the ad in an advertising pretesting context. Journal of Marketing, 53, 4865. doi: $10.2307 / 1251413$

MacKenzie, S. B., Lutz, R. J., \& Belch, G. E. (1986). The role of attitude toward the ad as a mediator of advertising effectiveness: A test of competing explanations. Journal of Marketing Research, 23, 130-143. doi: 10.2307/3151660

Martin, M. C. \& Gentry, J. W. (1997). Stuck in the model trap: The effects of beautiful models in ads on female pre-adolescents and adolescents. Journal of Advertising, 26(2), 19-33. doi: $10.1080 / 00913367.1997 .10673520$

McCombs, M. E. \& Shaw, D. L. (1972). The agenda-setting function of mass media. Public Opinion Quarterly, 36, 176-187. doi: 10.1086/267990 
Meyer, D. E. \& Schvaneveldt, R. W. (1971). Facilitation in recognizing pairs of words: Evidence of a dependence between retrieval operations. Journal of Experimental Psychology, 90, 227-234. doi: 10.1037/hh0031564

Morse, S. \& Gergen, K. J. (1970). Social comparison, self-consistency, and the concept of self. Journal of Personality and Social Psychology, 16, 148-156. doi: 10.1037/h0029862

Obermiller, C., Spangenberg, E. \& McLachlan, D. L. (2005). Ad skepticism: The consequences of disbelief. Journal of Advertising, 34(3), 7-17. doi: 10.1080/00913367.2005.10639199

Odin, Y., Odin, N., \& Valette-Florence, P. (2001). Conceptual and operational aspects of brand loyalty: An empirical investigation. Journal of Business Research, 53, 75-84. doi: 10.1016/S0148-2963(99)00076-4

O'Neil, A. (2014). A call for truth in the fashion pages: What the global trend in advertising regulation means for U.S. beauty and fashion advertisers. Indiana Journal of Global Legal Studies, 21(2), 619-641. Retrieved from http://www.repository.law.indiana.edu/cgi/viewcontent.cgi?article=1568\&context=ijgls

Paraskeva, N., Lewis-Smith, H., \& Diedrichs, P. C. (2015). Consumer opinion on social policy approaches to promoting positive body image: Airbrushed media images and disclaimer labels. Journal of Health Psychology, 22, 164-175. doi: 10.1177/1359105315597052

Pechmann, C. \& Knight, S. J. (2002). An experimental investigation of the joint effects of advertising and peers on adolescents' beliefs and intentions about cigarette consumption. Journal of Consumer Research, 29, 5-19. doi: 10.1086/339918

Reed, D. L., Thompson, J. K., Brannick, M. T., \& Sacco, W. P. (1991). Development and validation of the Physical Appearance State and Trait Anxiety Scale (PASTAS). Journal of Anxiety Disorders, 5, 323-332. doi: 10.1016/0887-6185(91)90032-O 
Richins, M. L. (1991). Social comparison and the idealized images of advertising. Journal of Consumer Research, 18, 71-83. doi: 10.1086/209242

Roberts, T. \& Gettman, J. Y. (2004). Mere exposure: Gender differences in the negative effects of priming a state of self-objectification. Sex Roles, 51, 17-27. doi: 10.1023/B:SERS.0000032306.20462.22

Rosenberg, M., Schooler, C., Schoenbach, C., \& Rosenberg, F. (1995). Global self-esteem and specific self-esteem: Different concepts, different outcomes. American Sociological Review, 60, 141-156.

Rodulfo, K. (2016). Aerie recruits real women for its latest \#AerieREAL campaign. Elle.com. Retrieved from http://www.elle.com/fashion/news/a38294/aerie-real-share-your-sparkcampaign/

Rubin, M. \& Hewstone, M. (1998). Social identity theory's self-esteem hypothesis: A review and some suggestions for clarification. Personality and Social Psychology Review, 2, 40-62. doi: 10.1207/s15327957pspr0201_3

Schachter, S. (1959). The psychology of affiliation. Stanford, CA: Stanford University of Press.

Scheufele, D. A. \& Tewksbury, D. (2007). Framing, agenda setting, and priming: The evolution of three media effects models. Journal of Communication, 57, 9-20. doi: $10.1111 / \mathrm{j} .1460 / 2466.2006 .00326 . \mathrm{x}$

Schlossberg, M. (2016a). Hollister is making major changes that are saving parent company Abercrombie \& Fitch. Business Insider. Retrieved from http://www.businessinsider.com/why-hollister-is-saving-abercrombie-2016-4 
Schlossberg, M. (2016b). This lingerie brand for young women refuses to airbrush ads - and sales are soaring 32\%. Business Insider. Retrieved from http://www.businessinsider.com/american-eagles-aerie-sales-2016-5

Schvaneveldt, R. W. \& Meyer, D. E. (1973). Retrieval and comparison processes in semantic memory. Attention and Performance, 4, 395-409.

Shaw, J. \& Waller, G. (1995). The media's impact on body image: Implications for prevention and treatment. Eating Disorders: The Journal of Treatment and Prevention, 3, 115-123. doi: 10.1080/10640269508249154

Slater, A., Tiggemann, M., Firth, B., \& Hawkins, K. (2012). Reality check: An experimental investigation of the addition of warning labels to fashion magazine images on women's mood and body dissatisfaction. Journal of Social and Clinical Psychology, 31, 105-122. doi: 10.1521/jscp.2012.31.2.105

Sohn, S. H. (2009). Body image: Impacts of media channels on men's and women's social comparison process, and testing of involvement measurement. Atlantic Journal of Communication, 17, 19-35. doi: 10.1080/15456870802505670

Sohn, S. H. \& Youn, S. (2013). Does she have to be thin? Testing the effects of models' body sizes on advertising effectiveness. Atlantic Journal of Communication, 21, 164-183. doi: $10.1080 / 15456870.2013 .803109$

Stewart, D. W. \& Martin, I. M. (1994). Intended and unintended consequences of warning messages: A review and synthesis of empirical research. Journal of Public Policy and Marketing, 13, 1-19. 
Stice, E., Schupak-Neuberg, E., Shaw, H. E., \& Stein, R. I. (1994). Relation of media exposure to eating disorder symptomatology: An examination of mediating mechanisms. Journal of Abnormal Psychology, 103, 836-840. doi: 10.1037/0021-843X.103.4.836

Stokes, S. (2002). Visual literacy in teaching and learning: A literature perspective. Electronic Journal for the Integration of Technology in Education, 1, 10-19.

Suls, J. \& Wheeler, L. (2012). Social comparison theory. Van Lange, P. A. M., Kruglanski, A. W. \& Higgins, T. (Eds.): Handbook of Theories of Social Psychology: Volume 1 (460482). London, UK: SAGE Publications Ltd.

Tantleff-Dunn, S., Barnes, R. D., \& Larose, J. G. (2011). It’s not just a “woman thing:” The current state of normative discontent. Eat Disorders: The Journal of Treatment and Prevention, 19, 392-402. doi: 10.1080/10640266.2011.609088

Tiggeman, M. \& McGill, B. (2004). The role of social comparison in the effect of magazine advertisements on women's mood and body dissatisfaction. Journal of Social and Clinical Psychology, 23, 23-44.

Tiggemann, M., Slater, A., \& Smyth, V. (2013). 'Retouch free': The effect of labelling media messages as not digitally altered on women's body dissatisfaction. Body Image, 11, 8588. doi: 10.1016/j.bodyim.2013.08.005

Torgerson, R. (2016). Here's what happened to American Eagle Aerie sales after it ditched Photoshop. US Magazine. Retrieved from http://www.usmagazine.com/celebritystyle/news/how-american-eagle-aeries-no-photoshop-campaign-affected-sales-w207279

Usmiani, S. \& Daniluk, J. (1997). Mothers and their adolescent daughters: Relationship between self-esteem, gender role identity, and body image. Journal of Youth and Adolescence, 26, 45-62. doi: 10.1023/A:1024588112108 
Velasquez, M. (2003). Debunking corporate moral responsibility. Business Ethics Quarterly, 13, 531-562. Retrieved from http://www.jstor.org/stable/3857970

Veldhuis, J., Konijn, E. A., \& Seidell, J. C. (2014) Counteracting media's thin body ideal in adolescent girls: Informing is more effective than warning. Media Psychology, 17, 154184. doi: 10.1080/15213269.2013.788327

Verified by UniDays: All students score 10\% off. Retrieved from https://www.hollisterco.com/webapp/wcs/stores/servlet/BrandExperienceView?catalogId $=10201 \&$ espotKey=Uniday\&langId=1\&storeId=10251\&cmp=PDS:HCO_US_GGL_BRD_General_Discount_Female_Exact_ C\&gclid=Cj0KEQiAgJTGBRDLr5_az_Ouk44BEiQAIxaA4jQtiWf_mhuxEl5P0xMOTL 2MZ5kwjddwsPXLgFrUpt4aAnU48P8HAQ

Wang, A. (2012). Visual priming of pharmaceutical advertising disclosures: Effects of a motivation factor. Corporate Communications: An International Journal, 17, 73-88. doi: $10.1108 / 13563281211196362$

Webb, N. J. \& Farmer, A. (1996). Corporate goodwill: A game theoretic approach to the effect of corporate charitable expenditures on firm behaviour. Annals of Public and Cooperative Economics, 67, 29-50. doi: 10.1111/j.1467.8292.1996.tb01946.x

Yi, Y. (1990). The effects of contextual priming in print advertisements. Journal of Consumer Research, 17, 215-222. doi: 10.1086/208551 
APPENDIX A: ADVERTISEMENT CONDITIONS

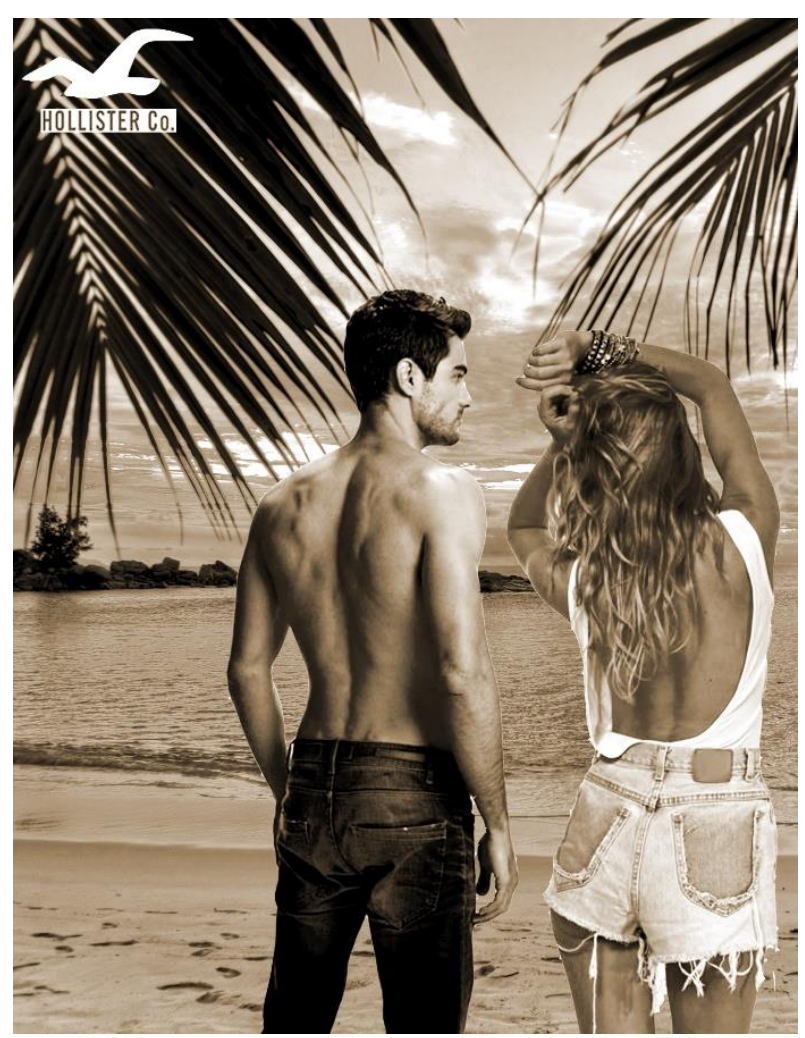

Thin Models - No Disclaimer

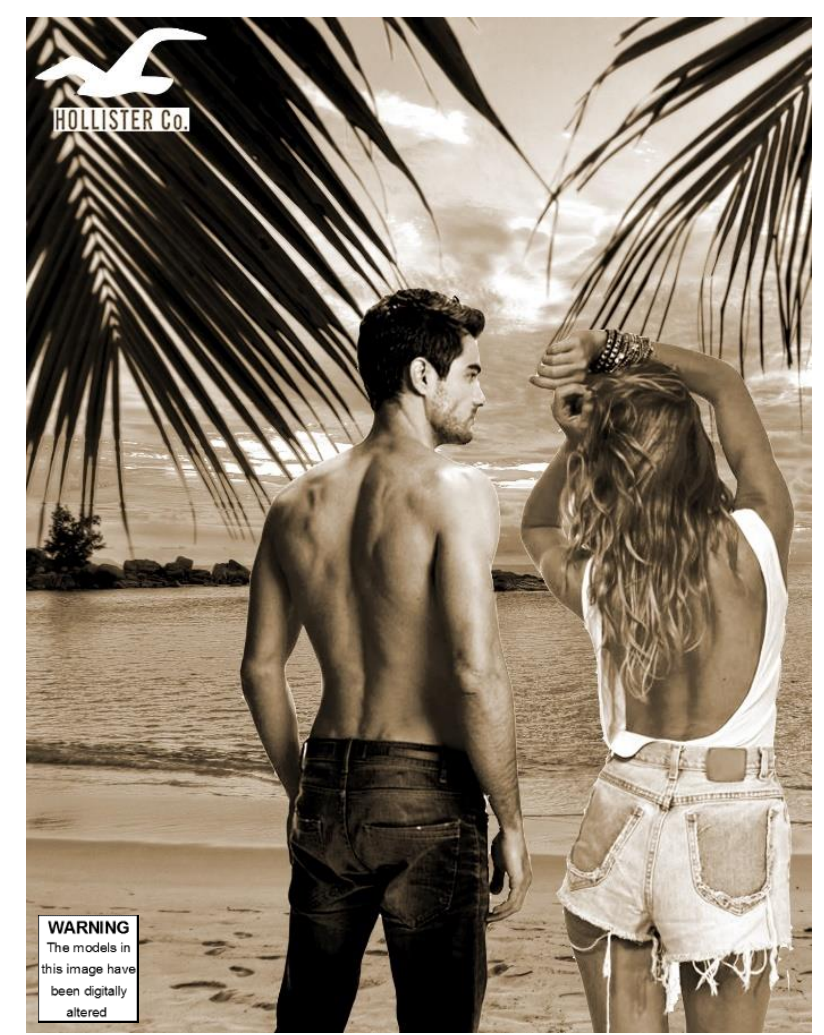

Thin Models - Presence Disclaimer 


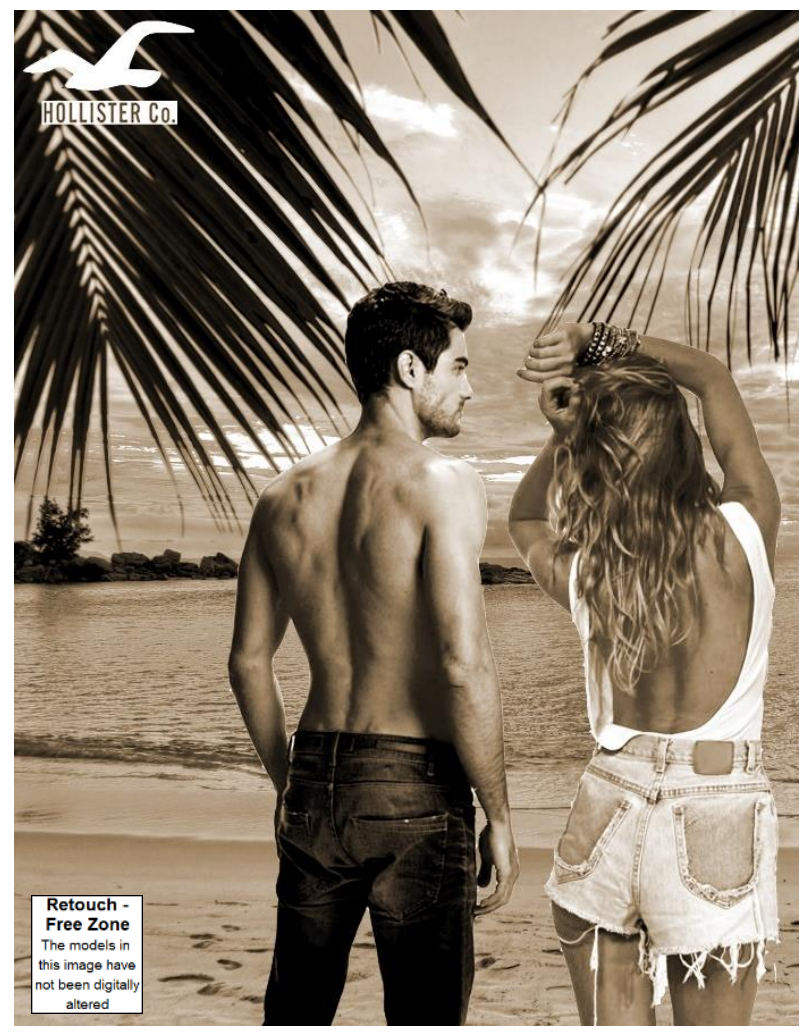

Thin Models - Absence Disclaimer

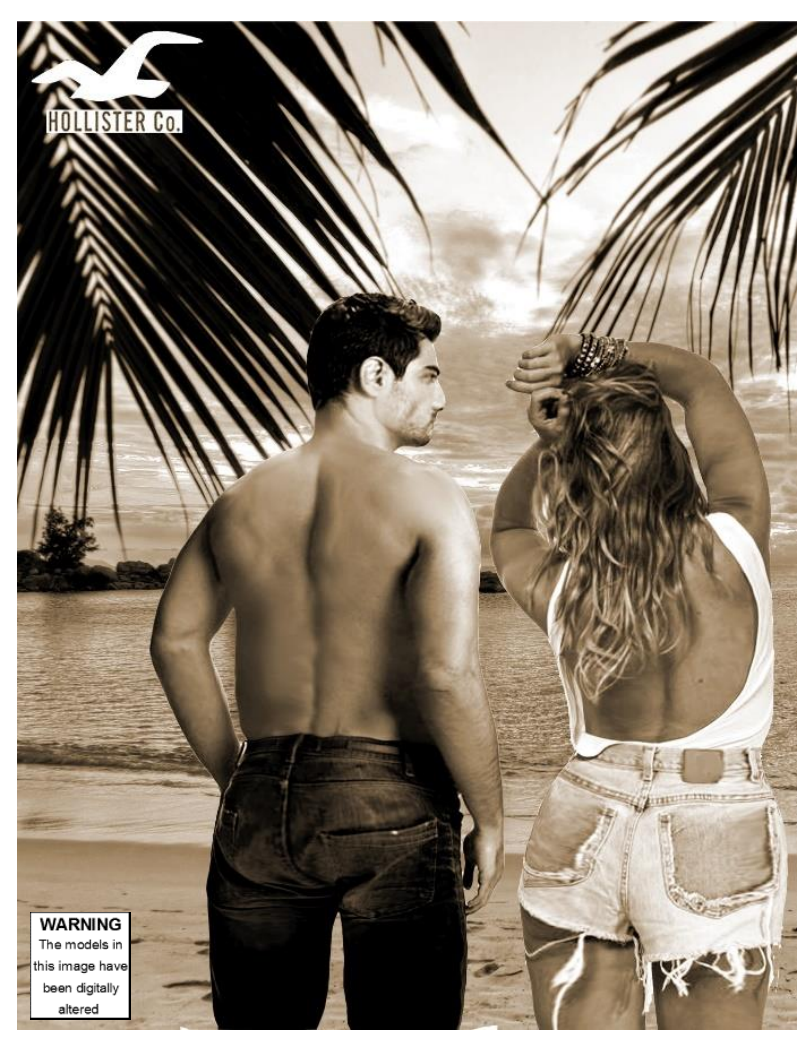

Average Models - Presence Disclaimer

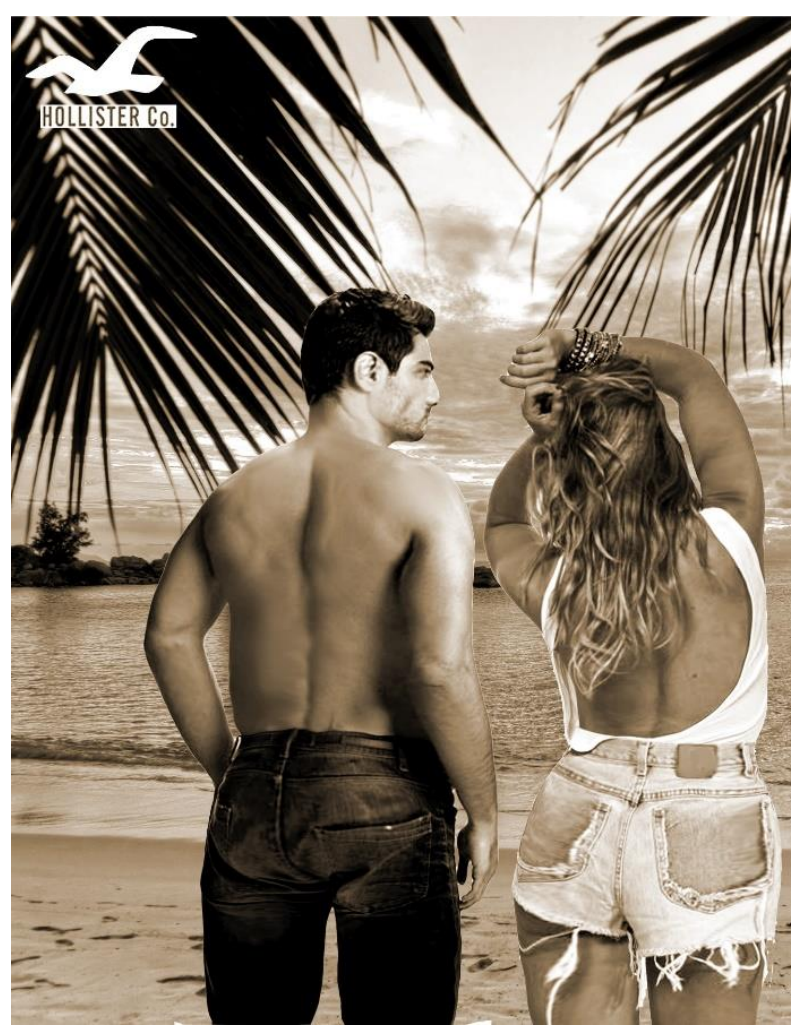

Average Models - No Disclaimer

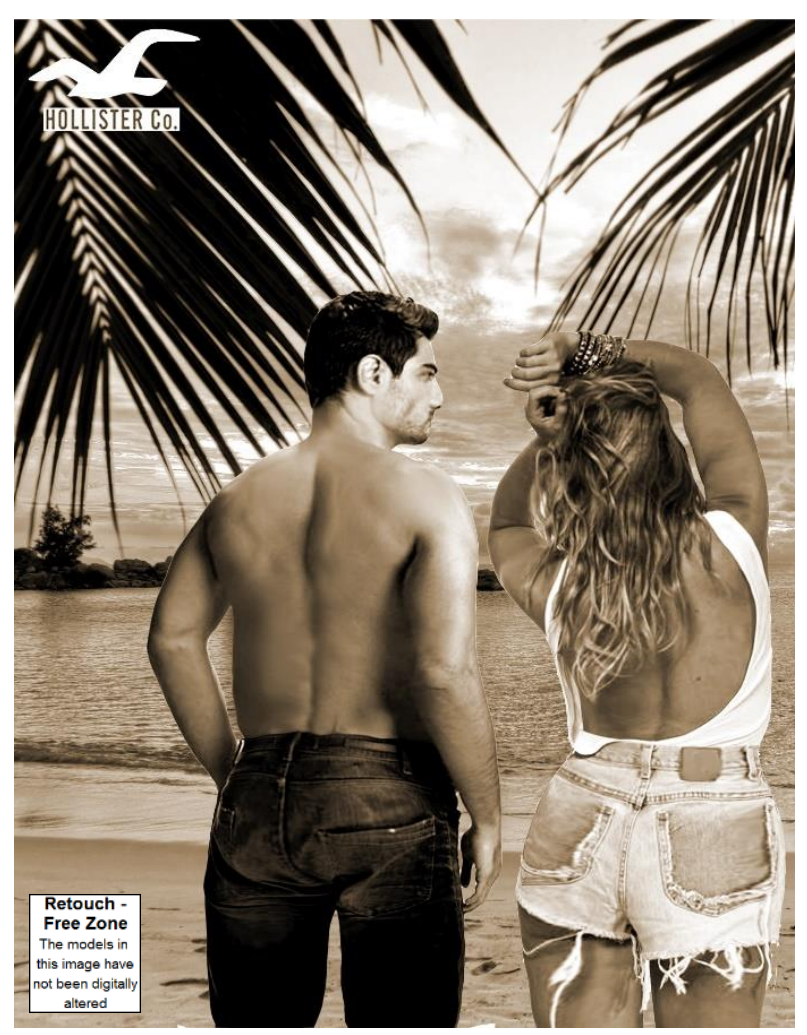

Average Models - Absence Disclaimer 


\section{APPENDIX B: STATE APPEARANCE COMPARISON SCALE}

(Tiggemann \& McGill, 2004)

1. How much did you think about your appearance when viewing the advertisement? No thought

1

2

3

45

A lot of thought

2. How often did you compare your appearance to the models you saw depicted in the advertisement?

No comparison

1 2

3

45

A lot of comparison 6 7

3. How often did you compare your specific body parts with those of the models you saw depicted in the advertisement?

No comparison

1

2

3

4

5

A lot of comparison

6

7 


\section{APPENDIX C: PHYSICAL APPEARANCE STATE ANXIETY SCALE}

(Reed, Thompson, Brannick, \& Sacco, 1991)

(1-15) The statements listed below are used to describe how anxious, tense, or nervous you feel right now about your body. Use the following scale:

Not at all Slightly $\quad$ Moderately

1 2
Very much so

4
Exceptionally so 5

1. The extent to which I look overweight

$\begin{array}{lllll}1 & 2 & 3 & 4 & 5 \\ 1 & 2 & 3 & 4 & 5 \\ 1 & 2 & 3 & 4 & 5 \\ 1 & 2 & 3 & 4 & 5 \\ 1 & 2 & 3 & 4 & 5 \\ 1 & 2 & 3 & 4 & 5 \\ 1 & 2 & 3 & 4 & 5 \\ 1 & 2 & 3 & 4 & 5 \\ 1 & 2 & 3 & 4 & 5 \\ 1 & 2 & 3 & 4 & 5 \\ 1 & 2 & 3 & 4 & 5 \\ 1 & 2 & 3 & 4 & 5 \\ 1 & 2 & 3 & 4 & 5 \\ 1 & 2 & 3 & 4 & 5 \\ 1 & 2 & 3 & 4 & 5\end{array}$




\section{APPENDIX D: WISHFUL IDENTIFICATION SCALE}

(Hoffner, 1996)

1. The models in the advertisement are the sort of people I want to be like myself. Strongly disagree

Disagree 2 Neutral 3 Agree 4 Strongly agree 5

2. I wish I could be more like the models in the advertisement. Strongly disagree 1 Disagree 2 Neutral 3 Agree 4 Strongly agree 5

3. I am similar to the models in this advertisement. Strongly disagree 1
Disagree

2
Neutral

3
Agree

4
Strongly agree 5 


\section{APPENDIX E: PERCEIVED ORGANIZATIONAL MORALITY}

(Leach, Ellemers, \& Barreto, 2007)

(1-3) How important do you perceive the following traits as being to the Hollister brand?

1. Honesty

$\begin{array}{llllllllll}\text { Not very important } & 1 & 2 & 3 & 4 & 5 & 6 & 7 & \text { Very Important }\end{array}$

2. Sincerity

$\begin{array}{llllllllll}\text { Not very important } & 1 & 2 & 3 & 4 & 5 & 6 & 7 & \text { Very Important }\end{array}$

3. Trustworthiness

$\begin{array}{llllllllll}\text { Not very important } & 1 & 2 & 3 & 4 & 5 & 6 & 7 & \text { Very Important }\end{array}$ 


\section{APPENDIX F: CREDIBILITY}

(MacKenzie \& Lutz, 1989)

Ad credibility

Below you will find a series of adjectives that represent your feelings about the advertisement displayed on the previous page. Based on your assessment, please indicate which best reflects how you feel.

$\begin{array}{lllllll}1 & 2 & 3 & 4 & 5 & 6 & 7 \\ \text { 1. Convincing } & - & - & - & - & - & - \\ \text { Unconvincing } \\ \text { 2. Believable } & - & - & - & - & - & - \\ \text { 3. Biased } & - & - & - & - & - & - \\ \text { Unbiased }\end{array}$

Advertiser credibility

Below you will find a series of adjectives that represent your feelings about Hollister Co. Please indicate which best reflects how you feel.

$$
\begin{array}{lllllll}
1 & 2 & 3 & 4 & 5 & 6 & 7
\end{array}
$$

4. Convincing _ _ _ _ _ _ Unconvincing

5. Believable $-\ldots-\ldots-\ldots$ Unbelievable

6. Biased ------- Unbiased

\section{Advertising in General}

Below you will find a series of adjectives that represent your feelings toward advertisements in general. Please indicate which best reflects how you feel.

7. Convincing _ _ _ _ _ _ Unconvincing

8. Believable _ _ _ _ _ _ Unbelievable

9. Biased $\quad-----\ldots-$ Unbiased 


\section{APPENDIX G: PURCHASING INTENTION}

(Dodds, Monroe, \& Grewal, 1991)

1. The likelihood of purchasing Hollister jeans is Very low Low Slightly Low Neutral $\begin{array}{ccccc}1 & 2 & 3 & 4 & 5 \\ \text { I were to buy jeans, I would consider buying Hollister jeans. }\end{array}$

2. If I were to buy jeans, I would consider buying Hollister jeans.
Very low Low Slightly Low Neutral Slightly High 1 2 3 4 5

High Very high $6 \quad 7$ High Very high

3. The probability that I would consider buying Hollister jeans is Very low Low Slightly Low Neutral Slightly High 1 2 3 4 5

High Very high 6 7

4. My willingness to buy Hollister jeans is Very low Low Slightly Low Neutral 1 2

Slightly High 5
High Very high

6 


\section{APPENDIX H: LOYALTY}

(Harris \& Ezeh, 2008)

1. Will you say positive things about these jeans to other people?

Very Likely Likely Kind of Likely Maybe Kind of Unlikely Unlikely Very Unlikely

$\begin{array}{lllllll}1 & 2 & 3 & 4 & 5 & 6 & 7\end{array}$

2. Will you recommend these jeans to someone who seeks your advice?

Very Likely Likely Kind of Likely Maybe Kind of Unlikely Unlikely Very Unlikely

$\begin{array}{lllllll}1 & 2 & 3 & 4 & 5 & 6 & 7\end{array}$

3. Will you encourage friends and relatives to do business with Hollister?

Very Likely Likely Kind of Likely Maybe Kind of Unlikely Unlikely Very Unlikely

$\begin{array}{lllllll}1 & 2 & 3 & 4 & 5 & 6 & 7\end{array}$

4. Will you consider Hollister as your first choice for jeans?

Very Likely Likely Kind of Likely Maybe Kind of Unlikely Unlikely Very Unlikely

$\begin{array}{lllllll}1 & 2 & 3 & 4 & 5 & 6 & 7\end{array}$

5. Will you do more business with Hollister in the next few years?

Very Likely Likely Kind of Likely Maybe Kind of Unlikely Unlikely Very Unlikely

$\begin{array}{lllllll}1 & 2 & 3 & 4 & 5 & 6 & 7\end{array}$

6. Will you buy Hollister jeans even if other brands are cheaper?

Very Likely Likely Kind of Likely Maybe Kind of Unlikely Unlikely Very Unlikely

$\begin{array}{lllllll}1 & 2 & 3 & 4 & 5 & 6 & 7\end{array}$




\section{APPENDIX I: DEMOGRAPHICS}

1. What is your age?

years old

2. What gender do you identify with?

female

male

other

I prefer not to disclose

3. Please specify your ethnicity.

Asian or Pacific Islander

Black or African American

Hispanic or Latino

Native American or American Indian

White or European

Other:

I prefer not to disclose

4. Have you ever owned a pair of Hollister jeans?

yes

no

5. Do you currently own a pair of Hollister jeans?

yes

no

6. What is your major? (Or say "undeclared") 